\title{
The short-term impact of price shocks on food security- Evidence from urban and rural Ethiopia
}

\author{
Julia Anna Matz ${ }^{1} \cdot$ Matthias Kalkuhl $^{1}$. Getachew Ahmed Abegaz ${ }^{2}$
}

Received: 9 April 2014 / Accepted: 10 April 2015 / Published online: 20 May 2015

(C) The Author(s) 2015. This article is published with open access at Springerlink.com

\begin{abstract}
This study investigates the impact of food price changes on food security in urban and rural Ethiopia. Using a quarterly household survey panel dataset and price data collected directly at markets, a negative effect of high cereal prices on some, but not all considered indicators of food security was found, controlling for unobserved heterogeneity across households. The results indicate that increases in cereal prices are generally, but not always, associated with households having a lower number of meals and switching to less preferred foods. Diet diversity and calorie consumption, however, show no clear response to grain price changes. Only partly in line with existing notions, our results suggest that the aggregate effect is negative for both the urban and rural populations (with the strongest among the urban poor) but that even poor households are able to maintain their basic food consumption through periods of moderate price changes.
\end{abstract}

Keywords Food price inflation $\cdot$ Food and nutrition security $\cdot$ Ethiopia

Electronic supplementary material The online version of this article (doi:10.1007/s12571-015-0467-4) contains supplementary material, which is available to authorized users.

Julia Anna Matz

jmatz@uni-bonn.de

1 Center for Development Research, University of Bonn, Walter-Flex-Str. 3, 53113 Bonn, Germany

2 Ethiopian Economics Association/Ethiopian Economic Policy Research Institute and International Food Policy Research Institute, Addis Ababa, Ethiopia

\section{Introduction}

Surprisingly little is known about the impact of food price changes on food and nutrition security (FNS) in the short term. In contrast, an extensive literature exists on the determinants of under- and malnourishment, which typically focuses on the roles of income (poverty), gender, feeding practices, access to clean water and sanitation, access to health services, or other socio-economic factors that do not change dramatically over short periods of time (Smith and Haddad 2000). The role of economic shocks, however, is only analyzed in a few studies that mostly compare differences in FNS indicators before and after a price, weather, or income shock (Kalkuhl et al. 2013). A major reason for this bias in scientific research is that understanding the impacts of shocks in an empirically solid manner requires longitudinal data with some variation over time, whereas the analysis of rather static socio-economic factors is easily possible with data collected at one point in time.

The aim of this paper, however, is to improve the understanding of the impacts of short-term price changes on food and nutrition security during the year. The difficulty in estimating the impacts of price changes arises from the need to have several observations for the same household over time. Cross-sectional variation in prices can hardly be exploited for empirical analysis as local prices may be correlated with other unobserved factors such as remoteness and regional taste, thus possibly leading to biased estimates. Likewise, the comparison of FNS indicators before and after a price change (or any other shock) has little explanatory power as other uncontrolled determinants may have changed simultaneously. A sound empirical analysis therefore requires the use of panel data that allow controlling for (unobserved) heterogeneity across households as well as time indicators. 
This paper uses quarterly panel data of urban and rural Ethiopian households between March 2012 and February 2013 to empirically investigate the impact of short-term price fluctuations on FNS. As anthropometric indicators are not available here, a number of consumption and perception based indicators are used to assess the change in household food security: the number of meals consumed, the consumption of less preferred foods, diet diversity, and calorie consumption. Overall, evidence for higher grain prices to be associated with a lower number of meals and a higher likelihood of consuming foods that the household does not prefer is found, but almost no association with diet diversity and calorie consumption. When investigating the effects in sub-samples according to income, wealth, and seasonality, heterogeneous effects are found, which illustrates the need to allow for differentiated impacts.

The reason for the widespread concern about food price increases impacting on FNS is the large share of food in household expenditure in developing countries. In Ethiopia, the setting of this study, households spent approximately 53 percent of their income on food in 2010/11, out of which staple cereals constitute the lion's share. To be specific, it was estimated that grains constituted 64.3 percent and 67.7 percent of the urban and rural average daily gross calorie intakes per adult equivalent, respectively (Federal Democratic Republic of Ethiopia Central Statistical Agency 2012). Furthermore, by far the most common responses of households in our sample, when asked how they responded to high food prices in the last five years, are that they reduced the amount and/or quality of food $(49.1 \%$ of the urban and $53.4 \%$ of the rural households stated this as one of their strategies to cope with high food prices) and that they reduced the number of meals per day $(53.4 \%$ of the urban and $47.6 \%$ of the rural households mentioned this as a coping strategy). ${ }^{1}$

The unexpected and dramatic increase of global prices for major food commodities in 2007 and the subsequent high volatility of food prices raised concerns about the impacts on FNS in developing countries. In many countries, global prices are transmitted to local food markets, albeit price transmission being imperfect and its intensity countrydependent (Robles 2011; Greb et al. 2012; Ianchovichina et al. 2012; Kalkuhl 2014). There have been a few attempts to estimate the impacts of the $2007 / 08$ price changes on FNS. Based on the FAO approach to calorie deficit con-

\footnotetext{
${ }^{1}$ In the urban sample, the other responses that were mentioned by more than $10 \%$ of the households were that they relied on less preferred and less expensive foods; that they borrowed food or relied on help from friends or relatives; and that they had purchased food on credit. In addition to these three, more than $10 \%$ of the rural households also mentioned the sale of assets, animals, or jewelry; and engaging in off-farm work as additional coping mechanisms.
}

sumption, Tiwari and Zaman (2010) calculated that an additional 63 million individuals became undernourished as a result of global food price spikes. With a similar focus on calorie intake, Anríquez et al. (2013) analyzed the impact of price increases on the number of calorie deficit people in eight selected countries. The authors found that in most of the considered countries calorie deficiency increased for the poorest households, both in rural and urban areas.

Our work is also related to another strand of research that emphasizes the close relationship between food prices, (real) income and poverty (see, e.g., Ticci 2011; Shimeles and Delelegn 2013; Tefera et al. 2013a, b for the case of Ethiopia and Headey 2014 for a recent global analysis): As food prices determine the (real) income of the population - positively for net sellers of food, negatively for net buyers - they can have substantial impacts on the distribution of income and on investment in natural, human, and physical capital. These factors, in turn, determine the prevalence of poverty which also affects the household's ability to purchase food. As the present study builds on existing research on the impact of food prices on income, poverty, and, thus, food security, the major pieces of work are briefly reviewed below. In contrast to these, however, our paper focuses on short-term dynamics, i.e. on price changes occurring within one year, including potential effects of seasonality.

A general challenge in this area of research is to distinguish between net buyers and net sellers of food commodities in most developing countries: while the former may experience a decrease in disposable income, the latter may benefit from price increases if they sell their surplus produce on the market. More specifically, net buyer households, which urban households usually are, are likely to be adversely affected by food price increases. On the other hand, cereal crops generally also take the major share of household production portfolio for rural farming households. An increase in the prices of these crops may therefore lead to an increase in the incomes of these households. As a result, the impact on this latter group of households remains an empirical question.

The decisions to buy and sell grains are determined by the prices of grains, however, and therefore endogenous so the differentiated effects are difficult to assess: Aksoy and Isik-Dikmelik (2008) found that price increases lead to an implicit income transfer from (on average better-off) urban citizens to (on average poorer) rural households, but they also lead to an absolute real income reduction for the poorest part of the rural population. While price increases may improve nutrition security for some of the poor rural population, they may simultaneously further worsen the food supply of those who are already food insecure. For this 
reason the effects on urban and rural households are investigated separately and differentiated effects within each sample allowed for.

Alem and Söderbom (2012) investigated which types of households in urban Ethiopia changed their food consumption significantly in 2008 when food prices were very high by investigating changes in consumption over three survey rounds in 2000, 2004 and 2008. They found that the high food price inflation was by far the most adverse economic shock between 2004 and 2008, and that a significant proportion of households adjusted food consumption in response. Their results indicate that households with low asset levels and casual workers were particularly adversely affected by high food prices. In contrast to our analysis, Alem and Söderbom (2012) did not use prices as explanatory variables but simply looked at changes in consumption.

Headey et al. (2012) also investigated the welfare impacts of rapid food price inflation in the cities and large rural towns of Ethiopia and tested whether casual wages in these predominantly urban areas adjusted to higher food prices. The authors found a sharp deterioration in the food purchasing power of wages between 2007 and 2008, when food prices first spiked, and again in 2011. During the 2007-2008 spike, the food purchasing power of casual wages declined by around 20 percent. To offer a comparison, the overall purchasing power, i.e. factoring in trends in non-food prices, only declined by around 10 percent.

Ticci (2011) studied the differential impact of food price increases between urban and rural households, however focusing on the period between 2006 and 2008. Assuming that income and consumption patterns remained unchanged, she found that, overall, urban poverty expanded and deepened. In rural Ethiopia, on the other hand, the picture was less conclusive due to a large part of the population producing food for self-consumption or sale. Shimeles and Delelegn (2013) suggest that a rise in relative prices of cereals leads to a large deterioration in the welfare of households in urban areas. However, their study found that land-rich households in rural areas tended to benefit significantly from a surge in food prices, while the land-poor and typical farm households tended to experience negative growth.

Tefera et al. (2013b) looked at the socioeconomic characteristics of rural households before and after the 2007/08 food price spike based on Ethiopian rural household survey panel data. Using a quadratic almost ideal demand system they found that gradual food price increases raised farming households' income which in turn resulted in stronger demand for high value and better quality food products, implying, at the aggregate level, an improvement in the welfare of rural households. In a related study, Tefera et al. (2013a) examined the distributional impact of rising food prices on the welfare of rural households in Ethiopia. Their findings indicate that high food prices improved the welfare (measured by consumption) of rural households at the aggregate level by about 0.3 percent from 2004 to 2009; which increased to 0.7 percent when substitution effects were accounted for, but that these welfare gains were not spread evenly among rural households. As expected, they found net cereal sellers to gain while net cereal buyers lose from price increases.

Other empirical studies focus on the implications of the 2007/08 price spikes for global poverty rates: Ivanic and Martin (2008), for instance, estimated that rising global prices have pushed 105 million additional people below the poverty line and, focusing on domestic food price increases until 2007, De Hoyos and Medvedev (2011) calculated that an additional 150 million people fell below the poverty line worldwide.

Besides the ones already mentioned, our work is related to the analyses of D'Souza and Jolliffe (2014), Iannotti and Robles (2011), Iannotti et al. (2012), and Jensen and Miller (2008b), but differs in the methodological approach as panel rather than cross-sectional data are used and the possibility of controlling for unobserved time-invariant heterogeneity across households is exploited. The paper is structured as follows: the following section gives a brief overview over the history of food price volatility and food price inflation in Ethiopia. Subsequently, the survey design and data are described. The empirical approach and results are discussed before the paper concludes.

\section{Food price changes in Ethiopia}

Figure 1 displays the development of quarterly wholesale price changes of grains in Addis Ababa between 2002 and 2013, where the shaded area indicates the time span of the household survey data used here. ${ }^{2}$ It is apparent that prices changed dramatically in 2008 but also show significant movement during the (relatively short and late) period of time studied. Besides periods of exceptional price increases, Fig. 1 also reveals strong seasonal patterns of price changes with price increases between April and October and sharp price falls around November and December. As discussed below, price dynamics at local markets (where we have only a short observation period) can differ substantially.

\footnotetext{
${ }^{2}$ Price changes are calculated as $\log$ returns, i.e. as $\log \left(r_{t}\right)=$ $\log \left(p_{t} / p_{t-1}\right)$, which is a standard approach to analyze price variability and volatility in time series analysis. As for $r_{t} \approx 1, \log \left(r_{t}\right) \approx r_{t}-1$, $\log$ returns are closely related to the relative change, or growth rate, of prices $p_{t} / p_{t-1}-1$. In contrast to growth rates, however, log returns can be added up over longer periods of time, i.e. $\log \left(p_{t} / p_{t-2}\right)=$ $\log \left(p_{t} / p_{t-1}\right)+\log \left(p_{t-1} / p_{t-2}\right)$, which allows easy calculation of cumulative price changes.
} 


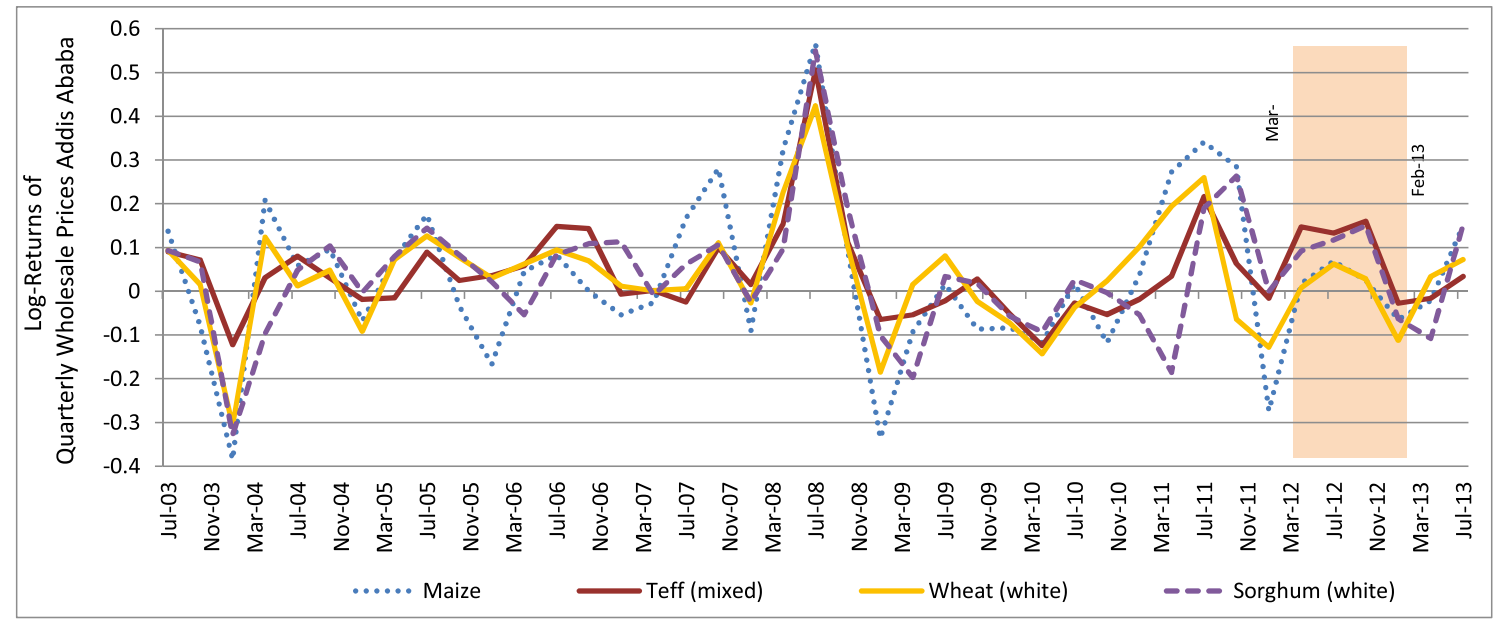

Fig. 1 Log returns of quarterly wholesale prices in Addis Ababa before and during the survey period. The shaded area denotes the time span of the survey used in this paper. Source: FAO GIEWS (2013)

Price increases were particularly high and prolonged in 2008 and 2011: Official data from the Federal Republic of Ethiopia Central Statistical Agency show that annualized food inflation equaled more than 60 percent in February 2009 , for example. The major contributor to this high food price inflation was cereal price inflation, which equaled 107 percent during the same period.

Several drivers have been identified for consumer and food price inflation (Ethiopian Economics Association 2011): increasing (international) energy and grain prices in 2007-08, an increase in the domestic money supply in 2007-08, and a further devaluation of the currency in 2010-11.

\section{Data}

\section{Survey design}

The data used for this study come from a panel household survey that was purposefully conducted to study the impact of food price inflation on the welfare of the poor. ${ }^{3}$ The data for the first round were collected in March and April of 2012, for the second round in June and July of the same year, for the third round in October and November of 2012, and the fourth round in January and February of the following year.

\footnotetext{
${ }^{3}$ This project was supervised by the Ethiopian Economics Association (EEA), and financed by the Center for Development Research (ZEF) of the University of Bonn and the Consortium of Christian Relief Development Association (CCRDA).
}

The dataset covers urban and rural households in four major regions of Ethiopia: Amhara, Oromiya, Tigray, and SNNPR, which include 86 percent of the total population (Federal Democratic Republic of Ethiopia Central Statistical Agency 2009) and account for more than 97 percent of the country's total grain production (Federal Democratic Republic of Ethiopia Central Statistical Agency 2013). The sample size for the rural dataset is approximately 450 households that were followed over time and from nine woredas (districts), which include Azerinet from SNNPR; Ofla from Tigray; Ankober, Habru, Gonder Zuria, and Yilmana Densa from Amhara; and Kombolcha, Arsi Negele, and Adea from Oromia. The urban part of the dataset has a sample size of approximately 350 households from eight towns: Dire Dawa, Kombolcha, Lera, Bahir Dar, Korem, Addis Ababa, Gorebella, and Butajira.

Kebeles, the smallest administrative units, were systematically selected in such a way that the nearest and the farthest kebeles from major towns were incorporated. The average distance of sites from the kebele centre is $15 \mathrm{~km}$ but varies from $3 \mathrm{~km}$ for Bilisuma to $42 \mathrm{~km}$ for Gorebella. The sampling frame was obtained from the administrative units of the kebeles and in cases where complete lists of households were not available in the kebele offices they were obtained from health and agricultural extension offices. Within each selected kebele, a random sampling technique was employed to select households. For the rural sample, it was assumed that kebeles have approximately the same population size and 25 households were included from each kebele. For the urban sample, due to the big variation in the size of towns in terms of population, the number of households to be randomly drawn from the list of households obtained from kebele administrative offices (in the 
case of large cities) or from city municipalities (in the case of smaller towns) was determined proportional to the size of the town.

The dataset includes, for example, information on household demographics, health and education, food and nonfood consumption expenditure, and perceptions of wellbeing. Furthermore, it covers production and income data, the size, type and utilization of land, credit and savings, household assets (including livestock ownership and housing), employment status, remittances, public aid, and time preferences of households. Together with the high frequency of data collection, the fact that households are followed over time make this dataset unique.

In addition to the household survey data, market price data were collected through the actual acquisition of grains at local markets, which is a major advantage over inferring price data from the reported expenditure patterns of households as done in most comparable studies due to the lack of 'real' price data. Even though the trend of prices in general is similar for all major commodities over time and across regions according to the Ethiopian Economics Association (2013), Fig. 2 displays the temporal and spatial variability of prices for the five major grains. While teff, a local and the most-consumed grain in Ethiopia, is the most expensive (exhibiting also large price increases), the median wheat and maize prices show less volatility during the time frame of the survey and over kebeles. Nevertheless, prices at individual markets may exhibit substantial fluctuations due to local demand and supply factors.

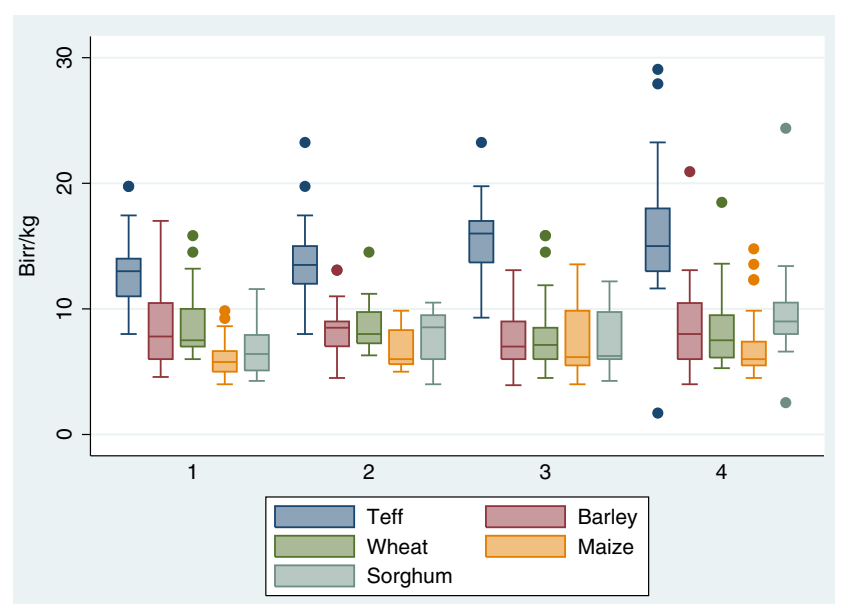

Fig. 2 Market prices over the four survey rounds in different kebeles. Note. The middle line inside the box plot indicates the median price over the different kebeles; the upper hinge of the box the 75th percentile and the lower hinge the 25th percentile. The ends of the lines outside the box refer to the smallest and largest values that are within 1.5 times the interquartile range; dots represent outliers. In 2012, the exchange rate was 17.70 Ethiopian Birr per US-Dollar (IMF, International Financial Statistics)
Although regional trade may reduce price differences, market integration in developing countries is not perfect and may depend on temporary and geographical conditions (Shin 2010). Table 1 displays the temporal and spatial variability of grain prices: Price differences between markets are much larger than price changes over time, indicating weak market integration and high transaction and transportation costs. Additionally, prices at local markets hardly co-move with wholesale market prices in Addis Ababa over the survey period: Apart from teff and wheat at some local markets, the pairwise correlation coefficients between local prices and wholesale prices are very low or even negative. Therefore, the development of mean commodity prices over the four survey rounds shown in Fig. 2 has to be interpreted with great caution as one cannot infer much about the overall price movement.

The large variability between local prices emphasizes the importance of using local prices instead of wholesale prices at central markets. Additionally, it increases the statistical power of the analysis due to the large variability of price changes over kebeles and over time.

\section{Summary statistics}

Table 2 presents summary statistics of all variables relevant for the analysis of the effects of grain price changes on nutrition outcomes in the urban sample, while Table 3 does the same for the households in the rural sample. Measures of food security used here are the number of meals currently eaten in a household per day, whether the household consumed foods in the past three months that it would normally not eat as they are less preferred (binary), a measure of diet diversity (a count of food groups covered by a household's reported consumption during the past week), ${ }^{4}$ and the number of calories consumed per adult equivalent unit (AEU) over the past week. ${ }^{5}$ According to Arimond

\footnotetext{
${ }^{4}$ Following Hoddinott and Yohannes (2002) the considered food groups are: "[...] country-specific basic staples [...]; country-specific "luxury staples" [...]; vitamin A-rich roots, tubers, vegetables, and fruits; beans, soya, and other pulses; dairy; fats; sugars; meat, fish, and eggs; other roots and tubers; other fruits; other vegetables; and beverages, spices, and other products" (Hoddinott and Yohannes 2002, p. 19-20).

${ }^{5}$ The variable meals per day is determined by the answer to the question of how often per day household member currently eat. The recall period for the questions whether, compared to the respondents' usual diet, they ate foods they ordinarily would not eat is 12 months for the first round of the survey and three months otherwise. Both the household's diet diversity and calorie consumption are based on the reported food consumption over the past seven days. When converting the reported food consumption into calories we follow the Food and Agriculture Organization of the United Nations (http://www. fao.org) and the Ethiopian Health and Nutrition Research Institute (http://www.ehnri.gov.et) for foods specific to Ethiopia.
} 
Table 1 Temporal variability (volatility), spatial variability and correlation of local grain prices

\begin{tabular}{llll}
\hline Grain & temporal variability $(\mathrm{CV})$ & spatial variability $(\mathrm{CV})$ & correlation with wholesale prices \\
\hline teff & $18.6 \%$ & $27.1 \%$ & $60.0 \%$ \\
wheat & $15.7 \%$ & $33.2 \%$ & $22.4 \%$ \\
sorghum & $19.6 \%$ & $31.2 \%$ & $-26.4 \%$ \\
maize & $16.5 \%$ & $31.6 \%$ & $5.9 \%$ \\
barley & $23.8 \%$ & $35.3 \%$ & not available \\
\hline
\end{tabular}

Temporal variability is calculated as the mean of the coefficients of variation $(\mathrm{CV})$ of prices per kebele; spatial variability is calculated as the mean of the coefficients of variations of prices per survey round/quarter; the correlation with wholesale prices in Addis Ababa is the mean of the pairwise correlation coefficients of local market prices from the survey and wholesale prices from FAO GIEWS (used in Fig. 1) over the four survey rounds. The pairwise correlation coefficients for each individual market are listed in the online supplementary material

and Ruel (2004), diet diversity is a good predictor of child nutrition in particular as it captures the quality of the diet regarding micro-nutrients in contrast to using calorie consumption. With respect to the number of calories consumed, significant measurement error is likely to exist in the raw data, especially with respect to the right tail of the distribution. Observations in the top $5 \%$ of the distribution of calories consumed are ignored for the analysis with respect to this variable but, even after this procedure, the data are still characterized by outliers and a large variance as shown in Tables 2 and 3.

It is worth noting the differences in the basic statistics of the measures of food security between the urban and rural samples. Even though urban consumers generally rely on buying food and rural households are often understood to be subsistence farmers, the former appear to be better off in

Table 2 Summary statistics of relevant variables - Urban sample

\begin{tabular}{|c|c|c|c|c|c|c|}
\hline & mean & $\min$ & $\mathrm{p} 50$ & $\max$ & $\mathrm{sd}$ & count \\
\hline meals per day & 2.8507 & 1 & 3 & 4 & 0.4394 & 911 \\
\hline less preferred food & 0.2400 & 0 & 0 & 1 & 0.4273 & 904 \\
\hline diet diversity & 8.5488 & 1 & 9 & 12 & 1.9134 & 911 \\
\hline calories per AEU & $17,760.56$ & 470.8333 & $15,728.29$ & $50,297.03$ & $9,816.732$ & 846 \\
\hline price_teff & 16.0847 & 1.7 & 14 & 50 & 8.9105 & 911 \\
\hline price_barley & 8.5523 & 4.5787 & 9 & 13.0821 & 1.9907 & 889 \\
\hline price_wheat & 8.2852 & 5.3 & 8 & 11.8812 & 1.7464 & 911 \\
\hline price_maize & 6.4165 & 4 & 6 & 11.0849 & 1.7980 & 862 \\
\hline price_sorghum & 9.0895 & 2.5385 & 6.7044 & 67.0440 & 10.889 & 739 \\
\hline price_index_hh & 168.7061 & 0 & 100 & $1,005.457$ & 207.7001 & 911 \\
\hline price_index_keb & 176.6013 & 44.3897 & 100 & 759.7846 & 195.3588 & 911 \\
\hline price_index_keb_exteff & 115.2521 & 45.8069 & 100 & 270.3774 & 42.3229 & 911 \\
\hline price_index_FAO & 120.5209 & 48.4771 & 100 & 293.3757 & 63.8762 & 911 \\
\hline assets & $1,9361.79$ & 0 & 5300 & $1,427,820$ & $70,763.96$ & 911 \\
\hline savings & $5,575.098$ & 0 & 0 & $1,500,000$ & $58,173.75$ & 911 \\
\hline bank account & 0.2327 & 0 & 0 & 1 & 0.42280 & 911 \\
\hline business income & $1,267.222$ & 0 & 0 & 78,000 & 4288.352 & 911 \\
\hline salary & $1,714.455$ & 0 & 190 & 193,500 & $8,195.52$ & 911 \\
\hline pension & 160.7194 & 0 & 0 & 8,660 & 642.1996 & 911 \\
\hline member credit assoc & 0.1120 & 0 & 0 & 1 & 0.3155 & 911 \\
\hline member equub & 0.2141 & 0 & 0 & 1 & 0.4104 & 911 \\
\hline own house & 0.2569 & 0 & 0 & 1 & 0.4371 & 911 \\
\hline household size in AEU & 0.9893 & 0 & 0 & 13.41 & 1.962371 & 911 \\
\hline orthodox & 0.5181 & 0 & 1 & 1 & 0.4999 & 911 \\
\hline muslim & 0.3820 & 0 & 0 & 1 & 0.4861 & 911 \\
\hline
\end{tabular}


Table 3 Summary statistics of relevant variables - Rural sample

\begin{tabular}{|c|c|c|c|c|c|c|}
\hline & mean & $\min$ & p50 & $\max$ & sd & count \\
\hline meals perday & 2.7222 & 1 & 3 & 4 & 0.4961 & 1105 \\
\hline less preferred food & 0.2961 & 0 & 0 & 1 & 0.4567 & 1101 \\
\hline diet diversity & 6.2671 & 1 & 6 & 12 & 2.4015 & 1097 \\
\hline calories per AEU & $17,896.34$ & 0 & $15,325.72$ & $63,764.15$ & $12,161.38$ & 986 \\
\hline price_teff & 15.0075 & 8 & 14 & 29.0698 & 4.2740 & 1105 \\
\hline price_barley & 8.4394 & 3.9246 & 8 & 20.9314 & 3.4010 & 969 \\
\hline price_wheat & 8.5022 & 4.5 & 7.3 & 18.4819 & 3.3193 & 1060 \\
\hline price_maize & 6.8630 & 4 & 6 & 14.7798 & 2.5260 & 1105 \\
\hline price_sorghum & 8.3121 & 4.3 & 7.3139 & 24.3796 & 3.3334 & 920 \\
\hline price_index_hh & 81.5753 & 0 & 95.4991 & 212.5 & 32.9105 & 1105 \\
\hline price_index_keb & 88.3970 & 33.2750 & 93.4584 & 148.8862 & 18.5323 & 1105 \\
\hline price_index_keb_exteff & 88.0302 & 27.3374 & 92.3971 & 157.109 & 19.6930 & 1105 \\
\hline price_index_FAO & 85.8496 & 37.8565 & 90.69 & 147.9698 & 15.8529 & 1105 \\
\hline assets & $4,924.001$ & 0 & 1,520 & 484,107 & $18,791.87$ & 1105 \\
\hline savings & 850.2498 & 0 & 0 & 108,000 & $4,622.98$ & 1105 \\
\hline area of land & 3.5217 & 0 & 0.875 & 400 & 22.5609 & 1105 \\
\hline livestock & $15,849.88$ & 0 & 9,720 & $1,103,000$ & $37,716.81$ & 1105 \\
\hline household size in AEU & 3.9976 & 0 & 3.9 & 10.86 & 1.8640 & 1105 \\
\hline psnp & 0.1068 & 0 & 0 & 1 & 0.3090 & 1105 \\
\hline member credit assoc & 0.1014 & 0 & 0 & 1 & 0.3019 & 1105 \\
\hline member equub & 0.0769 & 0 & 0 & 1 & 0.2666 & 1105 \\
\hline orthodox & 0.4226 & 0 & 0 & 1 & 0.4942 & 1105 \\
\hline muslim & 0.4968 & 0 & 0 & 1 & 0.5002 & 1105 \\
\hline
\end{tabular}

the case of Ethiopia. To be specific, urban households eat more meals per day and have greater variety in the types of food they consume than rural households on average, while they report consuming slightly fewer calories. Furthermore, they less often report eating foods that they would not normally eat due to a low preference for them. This is especially surprising when recalling that the data were collected in 2012 and 2013, when the food price crisis had already been ongoing for a number of years. Except for less preferred foods, inequality of FNS indicators measured as the coefficient of variation is higher for rural households than for urban households. It is reassuring to see that these measures of nutrition security behave as expected in relation to household income and wealth. To be specific, when the samples are separated into terciles according to income for urban and the sum of assets and savings for rural households, the number of meals increase, the likelihood of eating less preferred meals decreases, and diet diversity calorie consumption increase with income/wealth. ${ }^{6}$

Information on the prices of the five grains under investigation (teff, barley, wheat, maize, sorghum) obtained directly at local markets and of four composite price indices

\footnotetext{
${ }^{6}$ These tables are presented in the online supplementary material.
}

is also given. ${ }^{7}$ Despite the relative amounts of each grain consumed by a household in a survey period possibly being correlated with the respective prices and therefore endogenous, use of an unweighted index may also draw a distorted picture due to the importance of a grain (and its price) not being accounted for. For this reason, weighted indices are used with the price of each grain in the computation of the index weighed by its relative consumption in terms of the total expenditure share on grains at the household level averaged over the four periods (price_index_hh), by its average relative consumption in terms of the total expenditure share on grains at the kebele level over the four periods (price_index_keb), and by its relative nationwide consumption in terms of total calorie supply in 2008/09 according to the FAO (FAOSTAT 2013) (price_index_FAO). Teff is relatively expensive and its price exhibits extremely high variability at both urban and rural markets, also when compared to the other grains under investigation. In order to make sure the effects of the price indices are not exclusively driven by the price of teff, the price index weighted

\footnotetext{
${ }^{7}$ In order to account for different levels of the prices of different grains, the indices used here are scaled. In other words, the price for each grain is scaled to round 4 as the base round (in which there was the least amount of missing data) with a value of 100 and the values in the other rounds computed in relation to the base.
} 
by expenditure shares at the kebele level is amended by excluding the price of teff (price_index_keb_exteff). Due to consumption and price data not always being available, the indices are not necessarily based on all five prices. ${ }^{8}$

The value of a household's durable assets and current savings are given in Ethiopian Birr, where it should be noted that more than half of the households do not have any savings currently. Slightly less than a quarter of the households in the urban sample under investigation in Table 2 have a bank account but almost half of them run a business, leading to average business income of just over 1,200 Ethiopian Birr per month. Just over $52 \%$ of households have at least one member with a salary-earning job yielding average monthly earnings of over 1,700 Ethiopian Birr, while most households do not receive a pension and average income in the past three months from this source was 160 Ethiopian Birr. Just over $11 \%$ and $21 \%$ of the households in the urban sample are members of a credit association or equub (a credit and savings collective), respectively, and roughly a quarter own a house (member credit assoc, member equub and own house are all indicator variables). The size of the household is measured in adult equivalent units with a mean value of almost $4 .{ }^{9}$ Just over half of the households are Christian Orthodox and just over $38 \%$ Muslim.

Table 3 presents summary statistics for the rural sample. Most variables are identical to the ones used in the urban sample but some are adjusted for context. While business income or house ownership is not measured, the total area of the households' land holdings in hectares and the value of livestock holdings in Ethiopian Birr are included. On average, rural households have land holdings of 3.5 hectares and livestock worth almost 16,000 Ethiopian Birr. Furthermore, about $10 \%$ of households in the rural households have received support from the Productive Safety Nets Programme in the past three months ( $p s n p$ is an indicator variable).

\section{The effect of grain price changes on nutrition}

In order to investigate empirically whether changes in grain prices impact on different measures of FNS, the following equation is estimated, yielding the main results:

$$
Y_{h m t}=\alpha \text { ln }_{-} \text {price }_{m t}+\mathbf{X}_{h m t} \boldsymbol{\beta}+\boldsymbol{\Phi}_{h}+\boldsymbol{\Omega}_{t}+\epsilon_{h m t},
$$

\footnotetext{
${ }^{8}$ Furthermore, there are two cases of suspiciously large prices compared to observations from that market in the other periods and compared to other markets in the same period. Exclusion of the households close to that market (all in the urban sample) supports the main results and yields even stronger effects for one outcome variable (the number of meals consumed).

${ }^{9}$ In converting the composition of a household to household size in adult equivalent units we follow Dercon and Krishnan (1998).
}

where $Y_{h m t}$ denotes one of the dependent variables for household $h$ in survey period $t$ : the logarithmic value of the number of daily meals, whether less preferred foods were eaten, logarithmic food diversity, and the logarithmic value of the calories consumed per adult equivalent during the past week. $\ln _{-}$price is the key explanatory variable and denotes the logarithmic price of teff or an index of the prices of five commonly consumed grains at market $m$ in time period $t$. As discussed above, different indices weighed by consumption based on the prices of the following grains are investigated: teff, wheat, barley, maize, and sorghum. Due to high correlations in the prices and indices, separate regressions are run for each. It should be noted that the correlations between the dependent variables are not very high with a maximum of $33 \%$ in absolute terms so the results for different outcome variables should be understood as complementary. Besides having separate regressions for each dependent variable with each price (index), Eq. 1 is estimated separately for urban and rural households.

Time invariant unobserved heterogeneity across households, for example in preferences with respect to nutrition, is controlled for through the inclusion of household fixed effects $\boldsymbol{\Phi}$. This ensures that we focus on changes within rather than across households in response to grain price changes. In addition, $\mathbf{X}$ includes household characteristics that vary over time. For households from the urban sample these are household size in adult equivalent units and the logarithmic values of durable assets, savings, and income, where a value of one is added to the latter three before taking logarithms due to a number of cases reporting values equal to zero. Income may come from a salary-earning job, an own business or a pension. ${ }^{10}$ Further time variant household controls are included for whether or not the household owns a bank account or a house, and for whether the household is a member of a credit association or of an equub.

For households from the rural sample $\mathbf{X}$ is adjusted in order to allow for differences in context. It includes household size, assets, and savings as defined above, and the logarithmic values of the size of land and livestock holdings, both in addition to the value of one before applying the logarithmic transformation. With respect to binary variables used in the analysis of the rural sample, being a member of a credit association or equub as well as a dummy variable for whether anyone in the household has received any support from the Productive Safety Nets Programme in the

\footnotetext{
${ }^{10}$ The results of the main specification are robust to substituting in the number of children of a household rather than its size in adult equivalents. Furthermore, the size of the household as well as its holdings of assets and savings may, simultaneously to the dependent variable, be influenced by grain prices and therefore endogenous. Note that the results in Tables 4, 5, 6, 7, 8, 9, 10 and 11 are supported when these variables are excluded. The results are not presented for reasons of space but available from the authors upon request.
} 
Table 4 Regression coefficient estimates linking the number of meals consumed to grain prices - Urban sample

\begin{tabular}{|c|c|c|c|c|c|}
\hline & $\begin{array}{l}(1) \\
\text { main }\end{array}$ & $\begin{array}{l}(2) \\
\text { tercile } 1\end{array}$ & $\begin{array}{l}(3) \\
\text { tercile } 2\end{array}$ & $\begin{array}{l}\text { (4) } \\
\text { tercile } 3\end{array}$ & $\begin{array}{l}(5) \\
\text { deflated prices }\end{array}$ \\
\hline \multirow[t]{2}{*}{ ln_price_teff } & $-0.0143^{*}$ & $-0.0384^{*}$ & -0.0112 & 0.00557 & -0.00296 \\
\hline & {$[0.00858]$} & {$[0.0208]$} & {$[0.0140]$} & {$[0.00942]$} & {$[0.00738]$} \\
\hline \multirow[t]{2}{*}{ ln_price_index_hh } & -0.00876 & -0.0261 & 0.00856 & 0.00131 & 0.00784 \\
\hline & {$[0.0115]$} & {$[0.0363]$} & [0.0184] & {$[0.0108]$} & {$[0.00945]$} \\
\hline \multirow[t]{2}{*}{ ln_price_index_keb } & -0.0176 & $-0.0691^{* *}$ & -0.00254 & 0.0136 & 0.00412 \\
\hline & {$[0.0124]$} & {$[0.0334]$} & {$[0.0202]$} & {$[0.0141]$} & {$[0.00987]$} \\
\hline \multirow[t]{2}{*}{ ln_price_index_keb_exteff } & -0.0240 & $-0.0949^{*}$ & 0.0464 & 0.0436 & 0.00521 \\
\hline & {$[0.0266]$} & {$[0.0496]$} & {$[0.0458]$} & [0.0289] & [0.0242] \\
\hline \multirow[t]{2}{*}{ ln_price_index_FAO } & -0.0328 & $-0.0950^{* *}$ & -0.00192 & 0.0194 & -0.00556 \\
\hline & {$[0.0200]$} & {$[0.0425]$} & {$[0.0314]$} & [0.0219] & {$[0.0175]$} \\
\hline Household controls & Yes & Yes & Yes & Yes & Yes \\
\hline Household FE & Yes & Yes & Yes & Yes & Yes \\
\hline Round dummies & Yes & Yes & Yes & Yes & No \\
\hline$N$ & $882 \leq N \leq 911$ & $292 \leq N \leq 307$ & $295 \leq N \leq 303$ & $295 \leq N \leq 301$ & $882 \leq N \leq 911$ \\
\hline$R^{2}$ & $0.066 \leq R^{2} \leq 0.068$ & $0.143 \leq R^{2} \leq 0.154$ & $0.079 \leq R^{2} \leq 0.085$ & $0.085 \leq R^{2} \leq 0.096$ & $0.045 \leq R^{2} \leq 0.046$ \\
\hline
\end{tabular}

Robust standard errors in brackets. Separate regressions for each price (index); only the coefficient on the respective price (index) is reported for each regression

${ }^{*} p<0.10,{ }^{* *} p<0.05,{ }^{* * *} p<0.01$

past three months are included. $\boldsymbol{\Omega}$ includes indicator variables for the round of the survey the observation is from and $\epsilon$ is a statistical error term. ${ }^{11}$ Note that the inclusion of household fixed effects and survey round indicators yields a very 'strict' specification as everything that does not change within a household or survey round is controlled for, i.e. it is investigated what happens within households over time that is not "typical" of the survey round or household.

Tables 4, 5, 6, 7, 8, 9, 10 and 11 display the results for the different dependent variables in both the urban and rural samples separately and are organised in the same way: Column (1) always presents the results of estimating Eq. 1 separately for the price of teff or one of the price indices. For reasons of space, the results are presented in this compressed way, and only the coefficient and standard error of the main explanatory variable, the respective price (index),

\footnotetext{
${ }^{11}$ The survey round indicators control for nation-wide inflation, also for cooking costs, for example, or other overall price shocks that do not vary geographically or by type of food. This implies that the price of nutrition in general is implicitly included, which would be difficult to do directly due to substitution between types of food, which makes a decision on which prices to include difficult. Note that the results are robust to including the price of onions, another main ingredient in the Ethiopian cuisine, however. The results are not presented here for reasons of space but available from the authors upon request. Furthermore, Eq. 1 is estimated with robust standard errors. It may, however, be the case that the error variances are correlated across survey rounds within households. Please note that the results do not qualitatively change when this is allowed for in the estimation. Results are not presented but available from the authors upon request.
}

are presented from each set of results. Equation 1 is also estimated separately by terciles of economic wellbeing in order to investigate whether the effect found in column (1) differs by wealth of the household. To be specific, households in the urban sample are grouped according to mean income over the four survey periods and rural households according to the sum of assets and savings held due to the difficulty of measuring income in rural areas with the survey data used here. The results for wealth terciles 1,2 , and 3 are presented in columns (2), (3), and (4), respectively. ${ }^{12}$

As a sensitivity check, the main results are replicated without accounting for survey round-specific heterogeneity, i.e. $\boldsymbol{\Omega}_{t}$ is excluded and deflated prices, for which the base is March/April 2012 (the time of the first survey round), are used. ${ }^{13}$ The idea here is to not control for everything that is specific to a certain survey round, e.g. other shocks impacting on nutrition security in the whole sample at that point in time, but to only look at the effect of grain prices, deflated, of course, so as to exclude the possibility of inflation in general driving the effects. The disadvantage of survey round indicators is that price changes affecting all communities at the time of a survey round (e.g. overall price changes or price trends) are captured in these indicator variables and that the coefficients on the grain prices may therefore be

\footnotetext{
${ }^{12}$ Summary statistics for each wealth tercile are presented in the online supplementary material.

${ }^{13}$ Prices are deflated using the consumer price index of LABORSTA (see http://laborsta.ilo.org).
} 
Table 5 Regression coefficient estimates linking the number of meals consumed to grain prices - Rural sample

\begin{tabular}{|c|c|c|c|c|c|}
\hline & $\begin{array}{l}(1) \\
\text { main }\end{array}$ & $\begin{array}{l}(2) \\
\text { tercile } 1\end{array}$ & $\begin{array}{l}(3) \\
\text { tercile } 2\end{array}$ & $\begin{array}{l}\text { (4) } \\
\text { tercile } 3\end{array}$ & $\begin{array}{l}\text { (5) } \\
\text { deflated prices }\end{array}$ \\
\hline \multirow[t]{2}{*}{ ln_price_teff } & -0.0328 & 0.0485 & -0.0818 & -0.0877 & 0.0389 \\
\hline & {$[0.0386]$} & {$[0.0750]$} & {$[0.0561]$} & [0.0844] & {$[0.0417]$} \\
\hline \multirow[t]{2}{*}{ ln_price_index_hh } & $-0.0591^{* *}$ & 0.00227 & -0.101 & -0.0774 & -0.0260 \\
\hline & {$[0.0281]$} & {$[0.0610]$} & {$[0.0661]$} & {$[0.108]$} & {$[0.0230]$} \\
\hline \multirow[t]{2}{*}{ ln_price_index_keb } & $-0.122^{* *}$ & -0.0712 & $-0.230^{* * *}$ & -0.0637 & -0.0231 \\
\hline & {$[0.0493]$} & [0.0844] & {$[0.0759]$} & {$[0.0998]$} & {$[0.0418]$} \\
\hline \multirow[t]{2}{*}{ ln_price_index_keb_exteff } & $-0.130^{* * *}$ & -0.0924 & $-0.196^{* * *}$ & -0.0556 & $-0.0774^{* *}$ \\
\hline & {$[0.0417]$} & {$[0.0744]$} & {$[0.0628]$} & [0.0892] & {$[0.0388]$} \\
\hline \multirow[t]{2}{*}{ ln_price_index_FAO } & $-0.177^{* * *}$ & $-0.192^{*}$ & $-0.291^{* * *}$ & -0.0778 & -0.0621 \\
\hline & [0.0619] & [0.110] & [0.0949] & {$[0.115]$} & {$[0.0523]$} \\
\hline Household controls & Yes & Yes & Yes & Yes & Yes \\
\hline Household FE & Yes & Yes & Yes & Yes & Yes \\
\hline Round dummies & Yes & Yes & Yes & Yes & No \\
\hline$N$ & $1027 \leq N \leq 1130$ & $348 \leq N \leq 370$ & $335 \leq N \leq 368$ & $324 \leq N \leq 367$ & $1027 \leq N \leq 1130$ \\
\hline$R^{2}$ & $0.066 \leq R^{2} \leq 0.078$ & $0.074 \leq R^{2} \leq 0.085$ & $0.164 \leq R^{2} \leq 0.201$ & $0.086 \leq R^{2} \leq 0.107$ & $0.030 \leq R^{2} \leq 0.038$ \\
\hline
\end{tabular}

Robust standard errors in brackets. Separate regressions for each price (index); only the coefficient on the respective price (index) is reported for each regression

${ }^{*} p<0.10,{ }^{* *} p<0.05,{ }^{* * *} p<0.01$

downward biased estimates of the true effects of food price changes. The results of this sensitivity check are presented in column (5) of Tables 4, 5, 6, 7, 8, 9, 10 and 11. ${ }^{14}$

Naturally, the effects of price increases of grains are likely to differ depending on whether the household is a consumer, buyer or seller of a product. However, the decisions to consume, buy, and sell grains depend on the respective prices and are therefore potentially endogenous when the effect of price changes on nutritional outcomes of consumers and non-consumers, buyers and non-buyers, and sellers and non-sellers are investigated. For this reason this distinction is not explicitly incorporated in the analysis. ${ }^{15}$

\footnotetext{
${ }^{14}$ The effect of changes in prices that are found in the main results may also be driven by mere volatility, i.e. by the fact that prices are changing, or by the sign of the change, i.e. that increases have different effects than decreases. This is briefly investigated as well by separating price changes into the absolute change and the sign of the change and including an interaction term in Eq. 1. The results do not suggest that volatility is exclusively responsible for the adverse effects of price increases on the dependent variables as negative and positive price changes in many cases yield contrasting effects. The results are not shown but available from the authors upon request due to space considerations and this investigation being beyond the scope of this paper.

${ }^{15}$ Whether a household consumes, buys or sells a grain in relation to the price of that respective grain is briefly investigated in the online supplementary material, however.
}

\section{Number of meals}

\section{Urban households}

As shown in column (1) of Table 4, increases in the price of teff are associated with a reduction in the number of meals consumed in a household on a usual day as the coefficient on this variable is statistically significant and negative. ${ }^{16}$ To be precise, a $10 \%$-increase in the price of teff is associated with $0.14 \%$-decrease in the number of meals consumed. While these are not large numbers in themselves, it should be borne in mind that the median number of meals a day is three so that almost any coefficient that is statistically different from zero is economically meaningful. This is especially the case when the coefficient is converted into the share of households that cut their consumed number of meals back by one (see Appendix A for the derivation): In the urban sample, this happens for $1.2 \%$ of households when the price

\footnotetext{
${ }^{16}$ Due to the specific nature of the variable denoting the number of meals being count data, a Poisson regression model appears suitable as well. The results confirm the main results with the exception of one coefficient in the urban sample (see columns (1) and (2) of Table 15 in the Appendix). The coefficients for the rural sample (which are for both models mostly significant) are slightly smaller in the Poisson model. As a result of the fixed-effects Poisson regression approach dropping households with only one observation, i.e. households without variation over time, it is not the default approach for this dependent variable, however.
} 
Table 6 Regression coefficient estimates linking the consumption of less preferred foods to grain prices - Urban sample

\begin{tabular}{|c|c|c|c|c|c|}
\hline & $\begin{array}{l}(1) \\
\text { main }\end{array}$ & $\begin{array}{l}(2) \\
\text { tercile } 1\end{array}$ & $\begin{array}{l}(3) \\
\text { tercile } 2\end{array}$ & $\begin{array}{l}(4) \\
\text { tercile } 3\end{array}$ & $\begin{array}{l}(5) \\
\text { deflated prices }\end{array}$ \\
\hline \multirow[t]{2}{*}{ ln_price_teff } & $0.117^{* * *}$ & $0.149^{* * *}$ & $0.134^{* * *}$ & 0.0463 & $0.0672^{* * *}$ \\
\hline & [0.0249] & [0.0539] & {$[0.0363]$} & {$[0.0420]$} & {$[0.0235]$} \\
\hline \multirow[t]{2}{*}{ ln_price_index_hh } & $0.132^{* * *}$ & $0.196^{* *}$ & $0.114^{* *}$ & 0.0714 & $0.0581^{*}$ \\
\hline & [0.0329] & {$[0.0760]$} & {$[0.0444]$} & {$[0.0522]$} & {$[0.0312]$} \\
\hline \multirow[t]{2}{*}{ ln_price_index_keb } & $0.162^{* * *}$ & $0.243^{* * *}$ & $0.164^{* * *}$ & 0.0748 & $0.0661^{* *}$ \\
\hline & {$[0.0358]$} & {$[0.0763]$} & {$[0.0500]$} & {$[0.0596]$} & [0.0329] \\
\hline \multirow[t]{2}{*}{ ln_price_index_keb_exteff } & $0.197^{* * *}$ & $0.212^{*}$ & 0.163 & $0.194^{* *}$ & 0.0923 \\
\hline & [0.0649] & {$[0.115]$} & {$[0.115]$} & {$[0.0954]$} & {$[0.0621]$} \\
\hline \multirow[t]{2}{*}{ ln_price_index_FAO } & $0.234^{* * *}$ & $0.261^{* *}$ & $0.229^{* * *}$ & 0.156 & $0.126^{* * *}$ \\
\hline & {$[0.0545]$} & {$[0.105]$} & {$[0.0791]$} & {$[0.0962]$} & {$[0.0486]$} \\
\hline Household controls & Yes & Yes & Yes & Yes & Yes \\
\hline Household FE & Yes & Yes & Yes & Yes & Yes \\
\hline Round dummies & Yes & Yes & Yes & Yes & No \\
\hline$N$ & $889 \leq N \leq 918$ & $289 \leq N \leq 304$ & $292 \leq N \leq 300$ & $294 \leq N \leq 300$ & $889 \leq N \leq 918$ \\
\hline$R^{2}$ & $0.150 \leq R^{2} \leq 0.166$ & $0.240 \leq R^{2} \leq 0.261$ & $0.164 \leq R^{2} \leq 0.194$ & $0.202 \leq R^{2} \leq 0.211$ & $0.090 \leq R^{2} \leq 0.097$ \\
\hline
\end{tabular}

Robust standard errors in brackets. Separate regressions for each price (index); only the coefficient on the respective price (index) is reported for each regression

${ }^{*} p<0.10,{ }^{* *} p<0.05,{ }^{* * *} p<0.01$

of teff increases by $30 \%$, which is not a large hypothetical increase recalling Fig. 1.

Columns (2), (3), and (4) of Table 4 display the results for the number of meals in the urban sample in income terciles 1,2 and 3 , respectively. It is obvious that the main results found for the urban sample are driven by the tercile of the poorest households according to income. To, again, give an estimate of the number of households that reduce their number of meals by one: $3.2 \%$ and $5.7 \%$ of households in the lowest income tercile reduce

Table 7 Regression coefficient estimates linking the consumption of less preferred foods to grain prices - Rural sample

\begin{tabular}{|c|c|c|c|c|c|}
\hline & $\begin{array}{l}(1) \\
\text { main }\end{array}$ & $\begin{array}{l}(2) \\
\text { tercile } 1\end{array}$ & $\begin{array}{l}(3) \\
\text { tercile } 2\end{array}$ & $\begin{array}{l}(4) \\
\text { tercile } 3\end{array}$ & $\begin{array}{l}(5) \\
\text { deflated prices }\end{array}$ \\
\hline \multirow[t]{2}{*}{ ln_price_teff } & 0.116 & 0.0252 & 0.126 & 0.0990 & -0.0956 \\
\hline & {$[0.118]$} & {$[0.230]$} & [0.182] & {$[0.216]$} & {$[0.110]$} \\
\hline \multirow[t]{2}{*}{ ln_price_index_hh } & $0.113^{*}$ & 0.207 & 0.295 & -0.0244 & 0.0499 \\
\hline & {$[0.0676]$} & [0.159] & {$[0.238]$} & {$[0.224]$} & {$[0.0720]$} \\
\hline \multirow[t]{2}{*}{ ln_price_index_keb } & $0.263^{* *}$ & 0.223 & $0.447^{*}$ & -0.00252 & 0.0692 \\
\hline & {$[0.131]$} & [0.183] & {$[0.268]$} & {$[0.200]$} & [0.122] \\
\hline \multirow[t]{2}{*}{ ln_price_index_keb_exteff } & $0.269^{* *}$ & 0.225 & 0.395 & -0.0634 & $0.262^{* *}$ \\
\hline & {$[0.120]$} & {$[0.157]$} & {$[0.242]$} & {$[0.183]$} & {$[0.118]$} \\
\hline \multirow[t]{2}{*}{ ln_price_index_FAO } & $0.321^{* *}$ & $0.383^{*}$ & $0.517^{*}$ & 0.0274 & 0.201 \\
\hline & {$[0.141]$} & {$[0.215]$} & {$[0.280]$} & {$[0.223]$} & {$[0.135]$} \\
\hline Household controls & Yes & Yes & Yes & Yes & Yes \\
\hline Household FE & Yes & Yes & Yes & Yes & Yes \\
\hline Round dummies & Yes & Yes & Yes & Yes & No \\
\hline$N$ & $1028 \leq N \leq 1133$ & $346 \leq N \leq 368$ & $335 \leq N \leq 368$ & $322 \leq N \leq 365$ & $1028 \leq N \leq 1133$ \\
\hline$R^{2}$ & $0.110 \leq R^{2} \leq 0.136$ & $0.176 \leq R^{2} \leq 0.185$ & $0.127 \leq R^{2} \leq 0.143$ & $0.144 \leq R^{2} \leq 0.166$ & $0.042 \leq R^{2} \leq 0.053$ \\
\hline
\end{tabular}

Robust standard errors in brackets. Separate regressions for each price (index); only the coefficient on the respective price (index) is reported for each regression

${ }^{*} p<0.10,{ }^{* *} p<0.05,{ }^{* * *} p<0.01$ 
Table 8 Regression coefficient estimates linking diet diversity to grain prices - Urban sample

\begin{tabular}{|c|c|c|c|c|c|}
\hline & $\begin{array}{l}(1) \\
\text { main }\end{array}$ & $\begin{array}{l}(2) \\
\text { tercile } 1\end{array}$ & $\begin{array}{l}(3) \\
\text { tercile } 2\end{array}$ & $\begin{array}{l}(4) \\
\text { tercile } 3\end{array}$ & $\begin{array}{l}(5) \\
\text { deflated prices }\end{array}$ \\
\hline \multirow[t]{2}{*}{ ln_price_teff } & 0.00638 & 0.0219 & 0.00679 & -0.0191 & 0.00382 \\
\hline & {$[0.0111]$} & [0.0249] & {$[0.0212]$} & {$[0.0170]$} & [0.0104] \\
\hline \multirow[t]{2}{*}{ ln_price_index_hh } & -0.00699 & -0.0320 & -0.0121 & -0.0126 & -0.0159 \\
\hline & {$[0.0122]$} & {$[0.0278]$} & {$[0.0208]$} & [0.0182] & [0.0113] \\
\hline \multirow[t]{2}{*}{ ln_price_index_keb } & 0.00400 & -0.00651 & 0.0100 & -0.0264 & -0.00548 \\
\hline & {$[0.0151]$} & {$[0.0354]$} & {$[0.0280]$} & {$[0.0206]$} & {$[0.0136]$} \\
\hline \multirow[t]{2}{*}{ ln_price_index_keb_exteff } & -0.00871 & $-0.0894^{*}$ & 0.0262 & -0.0527 & -0.00775 \\
\hline & {$[0.0279]$} & {$[0.0511]$} & {$[0.0596]$} & {$[0.0476]$} & {$[0.0281]$} \\
\hline \multirow[t]{2}{*}{ ln_price_index_FAO } & -0.00340 & -0.0439 & 0.0198 & -0.0526 & 0.00714 \\
\hline & {$[0.0245]$} & {$[0.0489]$} & {$[0.0487]$} & [0.0359] & {$[0.0221]$} \\
\hline Household controls & Yes & Yes & Yes & Yes & Yes \\
\hline Household FE & Yes & Yes & Yes & Yes & Yes \\
\hline Round dummies & Yes & Yes & Yes & Yes & No \\
\hline$N$ & $896 \leq N \leq 925$ & $292 \leq N \leq 307$ & $295 \leq N \leq 303$ & $295 \leq N \leq 301$ & $896 \leq N \leq 925$ \\
\hline$R^{2}$ & $0.054 \leq R^{2} \leq 0.059$ & $0.105 \leq R^{2} \leq 0.120$ & $0.085 \leq R^{2} \leq 0.088$ & $0.137 \leq R^{2} \leq 0.150$ & $0.028 \leq R^{2} \leq 0.028$ \\
\hline
\end{tabular}

Robust standard errors in brackets. Separate regressions for each price (index); only the coefficient on the respective price (index) is reported for each regression

${ }^{*} p<0.10,{ }^{* *} p<0.05,{ }^{* * *} p<0.01$

their consumed number of meals by one if the prices of teff and the price index weighed by consumption at the kebele level increase by $30 \%$ - which is a large quantitative effect. It is also reassuring to see that the estimated price elasticities are higher for the indices than for teff as a substitution of teff for another, cheaper grain is

Table 9 Regression coefficient estimates linking diet diversity to grain prices - Rural sample

\begin{tabular}{|c|c|c|c|c|c|}
\hline & $\begin{array}{l}(1) \\
\text { main }\end{array}$ & $\begin{array}{l}(2) \\
\text { tercile } 1\end{array}$ & $\begin{array}{l}(3) \\
\text { tercile } 2\end{array}$ & $\begin{array}{l}\text { (4) } \\
\text { tercile } 3\end{array}$ & $\begin{array}{l}\text { (5) } \\
\text { deflated prices }\end{array}$ \\
\hline \multirow[t]{2}{*}{ ln_price_teff } & $0.137^{*}$ & $0.330^{* * *}$ & -0.0861 & 0.203 & $1.006^{* * *}$ \\
\hline & {$[0.0726]$} & {$[0.121]$} & [0.110] & [0.137] & [0.113] \\
\hline \multirow[t]{2}{*}{ ln_price_index_hh } & 0.0346 & 0.0672 & -0.0479 & $0.367^{* *}$ & $0.251^{* * *}$ \\
\hline & {$[0.0514]$} & {$[0.118]$} & {$[0.131]$} & {$[0.172]$} & {$[0.0806]$} \\
\hline \multirow[t]{2}{*}{ ln_price_index_keb } & 0.0708 & 0.0521 & -0.0453 & 0.290 & $0.797^{* * *}$ \\
\hline & {$[0.0840]$} & {$[0.142]$} & {$[0.141]$} & {$[0.202]$} & {$[0.0941]$} \\
\hline \multirow[t]{2}{*}{ ln_price_index_keb_exteff } & 0.0523 & 0.0160 & -0.00949 & 0.286 & 0.0645 \\
\hline & {$[0.0827]$} & [0.134] & {$[0.128]$} & [0.218] & {$[0.0975]$} \\
\hline \multirow[t]{2}{*}{ ln_price_index_FAO } & 0.158 & 0.103 & 0.119 & 0.202 & $0.895^{* * *}$ \\
\hline & [0.109] & {$[0.205]$} & {$[0.178]$} & [0.213] & [0.113] \\
\hline Household controls & Yes & Yes & Yes & Yes & Yes \\
\hline Household FE & Yes & Yes & Yes & Yes & Yes \\
\hline Round dummies & Yes & Yes & Yes & Yes & No \\
\hline$N$ & $1024 \leq N \leq 1129$ & $346 \leq N \leq 368$ & $331 \leq N \leq 364$ & $322 \leq N \leq 365$ & $1024 \leq N \leq 1129$ \\
\hline$R^{2}$ & $0.533 \leq R^{2} \leq 0.547$ & $0.543 \leq R^{2} \leq 0.562$ & $0.521 \leq R^{2} \leq 0.538$ & $0.617 \leq R^{2} \leq 0.630$ & $0.051 \leq R^{2} \leq 0.187$ \\
\hline
\end{tabular}

Robust standard errors in brackets. Separate regressions for each price (index); only the coefficient on the respective price (index) is reported for each regression

${ }^{*} p<0.10,{ }^{* *} p<0.05,{ }^{* * *} p<0.01$ 
Table 10 Regression coefficient estimates linking calories consumed to grain prices - Urban sample

\begin{tabular}{|c|c|c|c|c|c|}
\hline & $\begin{array}{l}(1) \\
\text { main }\end{array}$ & $\begin{array}{l}(2) \\
\text { tercile } 1\end{array}$ & $\begin{array}{l}(3) \\
\text { tercile } 2\end{array}$ & $\begin{array}{l}(4) \\
\text { tercile } 3\end{array}$ & $\begin{array}{l}(5) \\
\text { deflated prices }\end{array}$ \\
\hline \multirow[t]{2}{*}{ ln_price_teff } & -0.0452 & 0.0205 & $-0.0780^{*}$ & -0.0403 & -0.0404 \\
\hline & {$[0.0296]$} & {$[0.0739]$} & {$[0.0422]$} & {$[0.0544]$} & {$[0.0259]$} \\
\hline \multirow[t]{2}{*}{ ln_price_index_hh } & -0.0279 & -0.0647 & -0.0462 & 0.00554 & -0.0430 \\
\hline & {$[0.0355]$} & {$[0.0826]$} & {$[0.0462]$} & {$[0.0658]$} & {$[0.0300]$} \\
\hline \multirow[t]{2}{*}{ ln_price_index_keb } & -0.0496 & -0.0143 & -0.0776 & -0.0465 & $-0.0600^{*}$ \\
\hline & [0.0397] & {$[0.105]$} & {$[0.0506]$} & {$[0.0750]$} & {$[0.0325]$} \\
\hline \multirow[t]{2}{*}{ ln_price_index_keb_exteff } & 0.0128 & -0.102 & 0.0309 & 0.0188 & -0.0158 \\
\hline & {$[0.0678]$} & [0.113] & {$[0.126]$} & {$[0.159]$} & {$[0.0640]$} \\
\hline \multirow[t]{2}{*}{ ln_price_index_FAO } & -0.0930 & -0.195 & -0.144 & -0.0454 & -0.0754 \\
\hline & {$[0.0615]$} & [0.131] & [0.0917] & {$[0.122]$} & {$[0.0530]$} \\
\hline Household controls & Yes & Yes & Yes & Yes & Yes \\
\hline Household FE & Yes & Yes & Yes & Yes & Yes \\
\hline Round dummies & Yes & Yes & Yes & Yes & No \\
\hline$N$ & $831 \leq N \leq 860$ & $270 \leq N \leq 285$ & $282 \leq N \leq 290$ & $265 \leq N \leq 271$ & $831 \leq N \leq 860$ \\
\hline$R^{2}$ & $0.035 \leq R^{2} \leq 0.038$ & $0.065 \leq R^{2} \leq 0.077$ & $0.101 \leq R^{2} \leq 0.113$ & $0.126 \leq R^{2} \leq 0.130$ & $0.021 \leq R^{2} \leq 0.026$ \\
\hline
\end{tabular}

Robust standard errors in brackets. Separate regressions for each price (index); only the coefficient on the respective price (index) is reported for each regression

${ }^{*} p<0.10,{ }^{* *} p<0.05,{ }^{* * *} p<0.01$

possible without drastic changes to the type of dish consumed. Substituting for grains when their jointly measured price index is high is more difficult and therefore has more serious consequences for FNS. Interestingly, none of the price (indices) yield a statistically significant coefficient in the medium and top terciles, which illustrates that effects in different sub-samples may work in opposite directions and may cancel each other out when the total sample is considered. A differentiated investigation is therefore advisable.

The results of not including indicators for the survey rounds but to instead use deflated prices are presented in column (5) of Table 4. The conclusion drawn from the main results that an increase in the price of teff leads to a reduction in the number of meals consumed is not supported; none of the coefficients are statistically significantly different from zero. The same is the case when the number of meals without a logarithmic transformation of the dependent variable is used (see column (1) of Table 14 in the Appendix).

\section{Rural households}

The picture is only partly similar in the rural sample as displayed in column (1) of Table 5, which is organized in the same way as Table 4: The coefficient on the price of teff is not statistically significant but those on all price indices are (and negative). As teff is often considered a luxury good, rural consumers may be more willing to switch to other grains when the price of teff rises instead of cutting back on the number of meals. On the other hand, rural households could be producers of grains and therefore benefit from higher prices of teff, but, if that explanation were to hold, increases in the prices of other grains would probably not have adverse effects throughout. The magnitude of the coefficients is larger than in the urban sample: an increase in the price indices weighed by consumption at the household or kebele levels by $10 \%$ leads to decreases in the number of daily meals by $0.59 \%$ or $1.22 \%$, respectively. The fraction of households that consume one meal less is even larger $4.9 \%$ and $10 \%$, respectively - if these indices increase by $30 \%$.

The negative relationship is visually presented in Fig. 3, which plots the price index weighed by consumption at the kebele-level against the value of the average number of meals in a kebele that is not accounted for by the household fixed effects and survey round indicators, both for the urban and the rural samples. ${ }^{17}$ As shown, while

\footnotetext{
${ }^{17}$ To be specific, the fraction of the outcome variable that is not explained by the household fixed effects and survey round indicators is plotted (the remaining fraction is explained by the price impact and the error term; showing only a scatter plot of the original data would have little validity as important covariates would be neglected). As discussed in footnote 8 , there are some outliers in the price data. They have been excluded from the graphical presentation to enhance the visibility of the association between the price index and the indicators of food and nutrition security.
} 
Table 11 Regression coefficient estimates linking calories consumed to grain prices - Rural sample

\begin{tabular}{|c|c|c|c|c|c|}
\hline & $\begin{array}{l}(1) \\
\text { main }\end{array}$ & $\begin{array}{l}(2) \\
\text { tercile } 1\end{array}$ & $\begin{array}{l}(3) \\
\text { tercile } 2\end{array}$ & $\begin{array}{l}(4) \\
\text { tercile } 3\end{array}$ & $\begin{array}{l}(5) \\
\text { deflated prices }\end{array}$ \\
\hline \multirow[t]{2}{*}{ ln_price_teff } & -0.267 & -0.135 & -0.394 & -0.410 & $0.669^{* * *}$ \\
\hline & {$[0.205]$} & [0.302] & [0.319] & {$[0.576]$} & {$[0.227]$} \\
\hline \multirow[t]{2}{*}{ ln_price_index_hh } & 0.0625 & 0.0728 & -0.298 & 0.408 & $0.368^{*}$ \\
\hline & {$[0.165]$} & [0.391] & {$[0.338]$} & {$[0.473]$} & [0.194] \\
\hline \multirow[t]{2}{*}{ ln_price_index_keb } & -0.148 & -0.00137 & -0.549 & -0.497 & $0.826^{* * *}$ \\
\hline & {$[0.261]$} & {$[0.470]$} & {$[0.360]$} & {$[0.650]$} & {$[0.257]$} \\
\hline \multirow[t]{2}{*}{ ln_price_index_keb_exteff } & -0.192 & 0.0950 & -0.353 & -0.191 & 0.0555 \\
\hline & {$[0.258]$} & {$[0.447]$} & {$[0.331]$} & {$[0.668]$} & {$[0.252]$} \\
\hline \multirow[t]{2}{*}{ ln_price_index_FAO } & 0.0200 & -0.243 & -0.0190 & -0.196 & $0.806^{* *}$ \\
\hline & {$[0.327]$} & {$[0.589]$} & {$[0.426]$} & {$[0.788]$} & {$[0.332]$} \\
\hline Household controls & Yes & Yes & Yes & Yes & Yes \\
\hline Household FE & Yes & Yes & Yes & Yes & Yes \\
\hline Round dummies & Yes & Yes & Yes & Yes & No \\
\hline$N$ & $924 \leq N \leq 1014$ & $321 \leq N \leq 340$ & $305 \leq N \leq 334$ & $274 \leq N \leq 310$ & $924 \leq N \leq 1014$ \\
\hline$R^{2}$ & $0.217 \leq R^{2} \leq 0.247$ & $0.190 \leq R^{2} \leq 0.195$ & $0.327 \leq R^{2} \leq 0.357$ & $0.265 \leq R^{2} \leq 0.290$ & $0.041 \leq R^{2} \leq 0.068$ \\
\hline
\end{tabular}

Robust standard errors in brackets. Separate regressions for each price (index); only the coefficient on the respective price (index) is reported for each regression

${ }^{*} p<0.10,{ }^{* *} p<0.05,{ }^{* * *} p<0.01$

the association is less clear in the urban sample (recall that the coefficient on the price index was statistically insignificant in Table 4), it is rather obvious for the rural sample.

The main results are not fully replicated in terms of statistical significance for the rural sample when the sample is broken down by wealth terciles as presented in columns (2), (3), and (4) of Table 5, possibly due to the smaller sample sizes in the terciles as compared to column (1), but the results indicate that effects are almost exclusively found in the medium well-off tercile of households. Rich households may not suffer from price increases due to their ability to smooth consumption, while poor households may be unable to cut the number of meals further and possibly resort to other coping strategies that are investigated in the subsequent sections. ${ }^{18}$ When deflated prices are used and survey round indicators excluded, only one of the coefficients is statistically significant as presented in column (5) of Table 5.

\footnotetext{
${ }^{18}$ Note that the mean number of meals consumed in the poorest tercile in the rural sample is 2.6 , while the corresponding value is 2.7 in the urban sample and thereby almost identical to the mean number of meals consumed in the medium well-off rural sample (see the summary statistics for the different wealth terciles provided in the online supplementary material). Similarly, the fractions of the poorest and medium well-off rural terciles consuming one or two meals per day are $38.1 \%$ and $25.8 \%$, while the corresponding figures in the urban sample are $25.1 \%$ and $15.8 \%$
}

The effects of relaxing the assumption of constant price elasticity implicit with the use of logarithms for the dependent variable were also investigated. The main results are supported and suggest that an increase in the price index weighed by consumption at the kebele level by $10 \%$ is associated with a decrease in the number of meals by 0.03 on average (see column (2) of Table 14 in the Appendix). Again, this does not sound large, but it is sizeable when you recall that these are mean effects and that the median number of meals consumed per day is three.

\section{Consumption of less preferred foods}

An alternative dependent variable that is substituted in for $Y$ in Eq. 1 is a binary variable indicating whether or not the members of the household ate foods that are less preferred and normally not eaten. This is, therefore, a subjective measure relating to personal preference and not with regards to foods that are generally less preferred in Ethiopia, thus rendering a list redundant. Even though this variable is binary, the estimation strategy is still a household fixed effects technique rather than Probit or Logit, in which the inclusion of fixed effects is difficult due to the incidental parameters problem. Controlling for unobserved heterogeneity across households is necessary, however, in order to capture the effects of time invariant preferences and tastes in 
Fig. 3 Grain prices and the number of meals

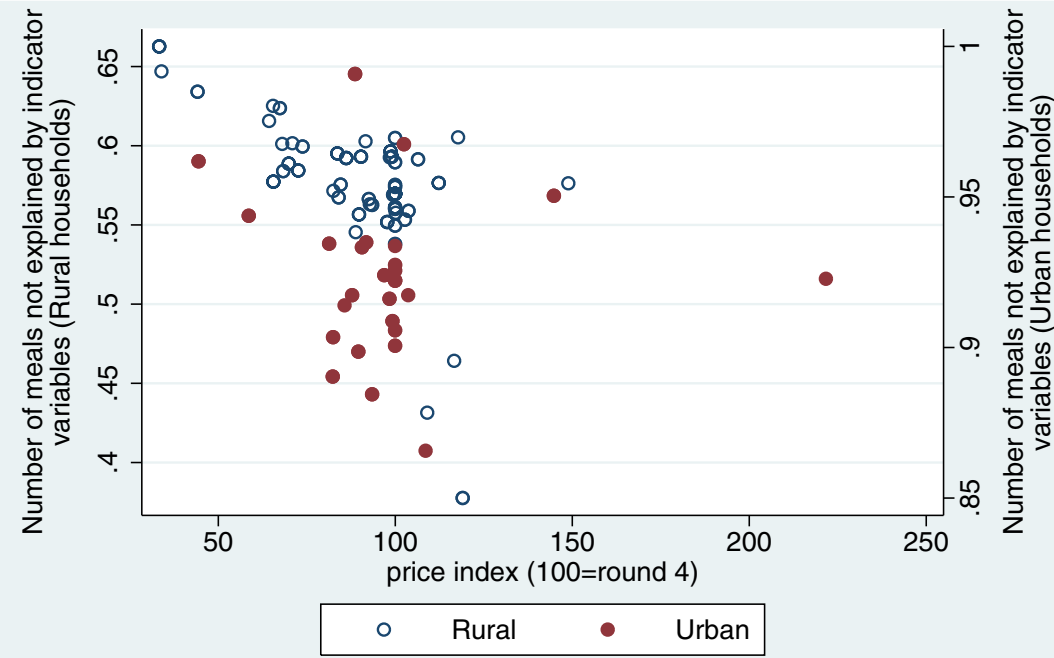

Note: The left and right axes denote the fractions of the values of the number of meals consumed in the rural and urban sample, respectively, that are not explained by the household fixed effects and survey round indicators. The price index used is
price_index_keb, i.e. the price index weighed by consumption at the kebele-level. households as outlined above. ${ }^{19}$ Note that an interaction term between being Orthodox and an observation being from the first round of the survey is included as the period of data collection took place during lent, which, for religious reasons, has an effect on the types of food but not the number of meals eaten by Orthodox Christians.

\section{Urban households}

The results of estimating (1) for the consumption of less preferred food in the urban sample are presented in column (1) of Table 6, which is organized in the same way as Table 4, i.e. each cell represents a set of separate regression results. Increases in the price of teff and all price indices used here lead to statistically significant and negative coefficients, which means that increases in grain prices are associated with a higher likelihood of a household consuming foods it prefers less. Due to the inability of fixed effects estimation to deal with binary dependent variables adequately, the absolute size of the coefficients is not meaningful. But when looking at the results of the conditional fixed-effects Logit specification, it can be seen that an increase in the price of teff by $10 \%$ increases the likelihood of consuming foods that are less preferred by $7.8 \%$ (see Table 15 in the Appendix).

The main results for the consumption of less preferred foods in the urban sample are driven by households in the

\footnotetext{
${ }^{19}$ Note that the main results reported in this section are replicated using a conditional fixed-effects Logit approach. The results of this alternative specification qualitatively support the main results presented in column (1) of both Tables 6 and 7 with the exception of one coefficient in the rural sample (see columns (3) and (4) of Table 15 in the Appendix).
}

bottom and medium income terciles as shown in columns (2), (3), and (4) of Table 6, with the coefficients being smaller in the middle one. In conjunction with the results for the number of meals this suggests that poorer urban households restrain the number of meals consumed and switch to less preferred foods, while the latter suffices for slightly better off households. Column (5) of Table 6 depicts the results when deflated prices are used. The main results are qualitatively supported apart from one coefficient being statistically insignificant.

\section{Rural households}

The picture looks less conclusive in the rural sample. As shown in column (1) of Table 7, the coefficients on all of the indices are statistically significant and positive. To give an idea of the magnitude of the effects, the results of the conditional fixed-effects Logit specification suggest that an increase in the price index with consumption weighed at the kebele-level by $10 \%$ increases the likelihood of consuming less preferred foods by $19 \%$. Similarly to Fig. 3, also the association between the likelihood of consuming less preferred foods and the price index weighed by consumption at the kebele-level is graphically presented (see Fig. 4). ${ }^{20}$ For this outcome variable, the positive relationship is apparent for both the urban and the rural samples in accordance with the results presented in Tables 6 and 7.

Only one coefficient is found to be statistically significant in the bottom and the medium wealth terciles as presented in columns (2), (3), and (4), however. Possible

\footnotetext{
${ }^{20}$ The corresponding figures for diet diversity and calorie consumption are to be found in the online supplementary material.
} 
Fig. 4 Grain prices and the likelihood of consuming less preferred foods

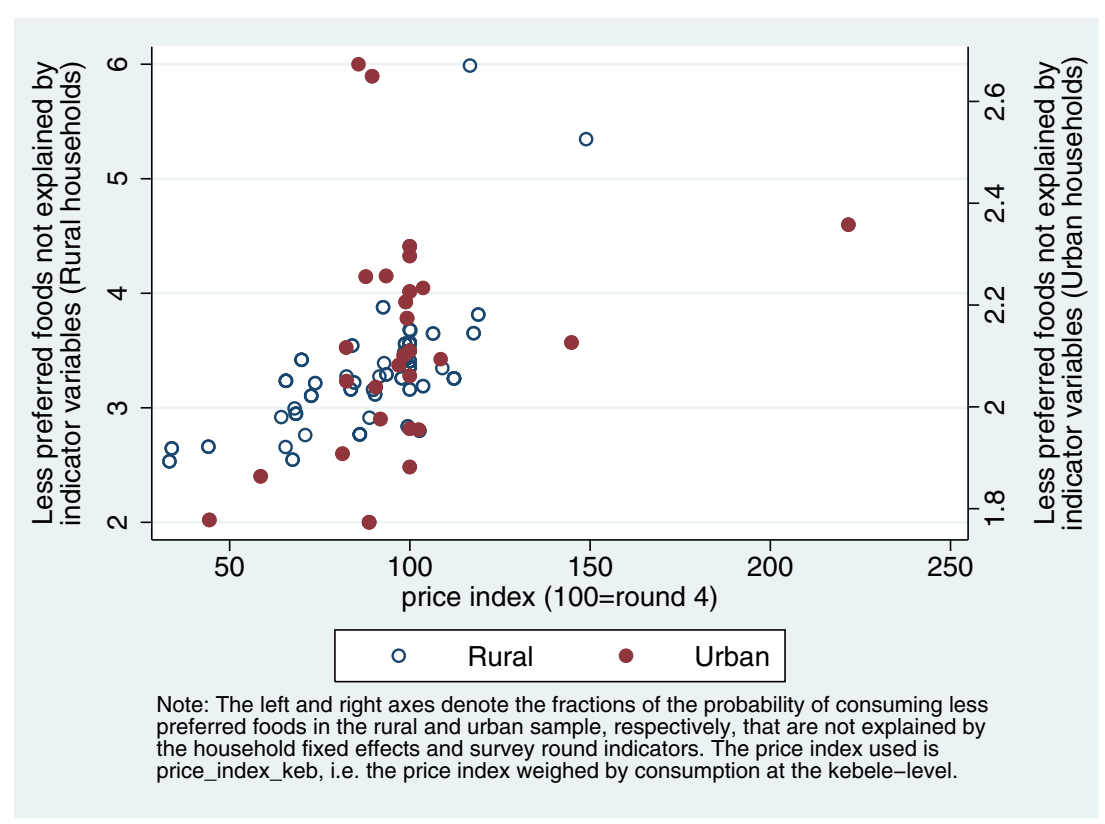

explanations may be that rural households rely more on home grown food or that, especially the poor ones, already consume foods that are less preferred. When survey round indicators are excluded and deflated prices used, the results suggesting a positive effect on the likelihood of consuming less preferred foods are weaker than the main results for the rural sample as presented in column (5) of Table 7.

\section{Diet diversity}

\section{Urban households}

When the logarithmic value of diet diversity is substituted into Eq. 1 as the dependent variable, no statistically significant effect was found in the urban sample as presented in column (1) of Table 8 . Note that, similarly to the specification for less preferred foods, an interaction between the household being Orthodox Christian and the data coming from round 1 is included. When looking into specific food groups, the data suggest that increases in the prices of grains lead to a higher consumption of sugars and vegetables, and to an opposite effect of changes in the prices of teff and other grains on the consumption of roots, tubers, vegetables, and fruits that are rich in vitamin A (positive for the price of teff, negative for the weighted index of all other grains). Furthermore, there is some evidence that increases in grain prices lead to a lower consumption of dairy products and fruits. $^{21}$

\footnotetext{
${ }^{21}$ The results for the specific food groups are not presented for reasons of space but available from the authors upon request.
}

Columns (2), (3), and (4) present the results in income terciles 1,2 , and 3 , respectively. The effects are rather weak but show one statistically significant and negative coefficient in the low income tercile, which is in line with expectation as diet diversity is an indicator of nutrition quality. Without controlling for the survey round, there are again no statistically significant coefficients as presented in column (5) of Table 8. Furthermore, the results are robust to not taking the logarithmic value of diet diversity as the dependent variable (see column (3) of Table 14 in the Appendix).

\section{Rural households}

In the rural sample, price increases for grains exhibit a statistically significant and positive effect on diet diversity for the price of teff and no statistically significant effect of increases in any of the price indices as displayed in column (1) of Table 9. While the positive sign may originate from the fact that rural households sell more than they buy, there is no evidence for a positive association of higher prices of teff with the other measures of nutritional outcomes as discussed above. Therefore, it is likely that households diversify their nutrition to include foods they would not normally eat as they are relatively cheap compared to teff, for example other, cheaper grains.

The results broken down by asset tercile are presented in columns (2), (3), and (4) of Table 9. The effect found in the main results is driven by households in the bottom wealth tercile, while a statistically significant and positive 
coefficient is also found for households in the top tercile, which is support for the existence of both an income and a substitution effect. While relatively rich households may benefit from higher grain prices due to being net sellers and therefore diversify into luxury foods, poor households may be adversely affected and forced to switch to types and groups of food that are less preferred, which is in line with expectation as diet diversity is a measure of nutrition quality that should decrease when in financial distress.

This is in fact supported when looking at the effect on specific food groups. Positive effects of increases in grain prices are found for whether beans, soya, and other pulses; fats; sugars; dairy products; and vegetables that are not rich in vitamin A are consumed, which again points to both an income and a substitution effect. Mixed effects are found for whether meat, fish, and eggs (positive for the price of teff, negative for the price index of all other grains), and whether roots and tubers that are not rich in vitamin A are consumed (negative for the price of teff, positive for all price indices).

When the indicators for survey round are not included in column (5) of Table 9, three of the four price indices are statistically significant and positive in addition to the price of teff. As elaborated below when discussing seasonality, diet diversity and calorie consumption for the rural sample are lowest in the first round (a few months after harvest in many kebeles), where prices of teff, maize and sorghum are (averaged over all kebeles) lowest. Lower food expenditure is, however, driven by high investment the coming harvest season. The conjunction of low prices and low diet diversity therefore creates a spurious correlation which is avoided when round dummies are considered. Using simply the count value of diet diversity rather than its logarithmic one, the results are robust apart from the price of teff, whose coefficient is now also statistically insignificant (see column (4) of Table 14 in the Appendix).

\section{Calorie Consumption}

As a next step, Eq. 1 is amended by substituting in the logarithmic value of the number of calories consumed within the household per adult equivalent unit during the past week for $Y{ }^{22}$ As mentioned when describing the data, observations in the top $5 \%$ are excluded but the data still exhibit extreme values and a high variability so that the results

\footnotetext{
${ }^{22}$ Note that an interaction term between being Orthodox and an observation being from the first round of the survey is, again, included. There are two cases in the rural sample that report a calorie consumption of zero. As this constitutes a likely case of misreporting, the fact that the logarithmic transformation leads to these two observations being dropped is accepted.
}

reported in this section should be interpreted with care and regarded as complementary to the results for the other outcome variables outlined above. It is not unusual for data on calorie consumption to exhibit very large variability and measurement error (Smith and Subandoro 2007), however, so we believe reporting our results still adds to the picture.

In order to test the validity of the results and to investigate the (possibly endogenous) response of the consumption of cereals to changes in their prices, Eq. 1 is also investigated with the logarithmic value of the calories consumed from grains only per adult equivalent as the dependent variable. The effect may be working in opposite directions: While an increase in the price of a normal good should lead to a reduction in the quantity consumed, grains may show properties of a Giffen good (Jensen and Miller 2008a) and a lower budget for food items may lead to worse nutrition quality, for which a high share of grains is indicative as staples are relatively cheap considering their nutritional values but do not offer a variety of nutrients. The picture drawn by the main results of this section is supported by this amended specification. ${ }^{23}$

\section{Urban households}

The estimation results for Eq. 1 and calorie consumption as the dependent variable in the urban sample are presented in column (1) of Table 10 and do not show evidence for a statistically significant relationship of the price of teff or any of the price indices with calories consumed per adult equivalent. Columns (2) through (4) replicate the results in sub-samples of income terciles 1 through 3 . Similarly to the results for the complete urban sample, with the exception of one in column (3), all coefficients are statistically insignificant. When the survey round indicators are excluded and deflated prices used in column (5), the picture is qualitatively almost identical to column (1). The same applies when the dependent variable has not undergone logarithmic transformation (see column (4) of Table 14 in the Appendix).

\section{Rural households}

The picture hardly changes when the effects for the rural sample of households are investigated as presented in Table 11: the coefficients on the price of teff and all indices are statistically insignificant.

\footnotetext{
${ }^{23}$ The results are presented in columns (5) and (6) of Table 15 in the Appendix.
} 
Columns (2), (3), and (4) report the results for terciles of households according to the sum of their asset holdings and savings. Again, none of the coefficients is statistically significant, which is surprising but in line with the explanation by D'Souza and Jolliffe (2014) who argue that price increases in wheat do not lead to reductions in calorie consumption among the poor of the population, who are most likely unable to cut back on calories further but opt to reduce diet quality. When deflated prices are used in column (5) of Table 11, four out of five coefficients are statistically significant but positive, which illustrates the importance of including survey round indicators (the same explanation as in the case of diet diversity for the rural population holds). When calories consumed are directly used as the dependent variable, the coefficient on the price of teff becomes statistically significant and positive, the coefficients on all indices remain statistically insignificant (see column (6) of Table 14 in the Appendix).

\section{Seasonality}

The quarterly panel used here also allows shedding of some light on seasonal patterns of food security indicators. ${ }^{24}$ Table 12 presents the mean values of the four indicators of FNS for the urban and the rural samples in each of the rounds. The bottom row furthermore depicts the seasonal variation of the mean values as a coefficient of variation. Note that the survey covers only four quarterly rounds within one year, which demands a cautious interpretation of the role of seasonality as singular events cannot be controlled for. Hence, we are unable to relate changes over the survey rounds to seasonal effects rather than to other events in a rigorous statistical manner. Nevertheless, Table 12 indicates that seasonal variation for diet diversity and calorie consumption is much stronger for the rural population than for the urban one.

Table 12 also suggests that the food security situation improves in the third and the fourth rounds, which cover the major harvesting season (depending on the crop and location, harvest starts in the third round and finishes by January at the latest). The first two rounds cover the lean season which is normally considered to be the season with the worst food security situation (the 'hungry season'). However, as there is a second minor harvesting season in many places, i.e. the belg season between the months of March and August, smaller supplies setting in during this period may improve access to food for many households in round 2 .

\footnotetext{
${ }^{24}$ We thank an anonymous referee for suggesting a closer look into this issue.
}

The data in Table 12 indicate that the season following the harvesting season (round 1) is the one which looks worst with respect to the investigated food security indicators, in particular for rural households. The second round shows moderate levels, and rounds 3 and 4 are characterized by the highest food and nutrition security statuses (as expected).

Other factors inferring with seasonal harvesting patterns may be related to fasting practices (although the low values for calorie consumption and diet diversity are also found in non-orthodox households) or payments from the productive safety net program (PNSP). Another explanation for the strong seasonal pattern in the rural sample is that farmers spend a large share of their income after the main harvest on agricultural inputs and hired labor for the next cropping season: The household data used here reveal that expenditures for fertilizers and seeds are highest in the first round when planting takes place and farmers prepare their fields. Hence, households seem to be seriously credit-constrained in the first round to ensure sufficient investments for the later harvest, which generates their income. ${ }^{25}$

As the focus of this paper is on the role of food prices for FNS, we are particularly interested whether grain prices influence food security differently in different seasons and concentrate only on the indicators that show high seasonal variation (disregarding the number of meals). Rounds 1 and 2 are grouped together as well as rounds 3 and 4 and it is investigated whether the price elasticity in the harvesting season (rounds 3 and 4) is different from the overall price elasticity. ${ }^{26}$ This procedure allows identification of whether price changes during the lean season (rounds 1 and 2) have different impacts than price changes in the harvesting season (rounds 3 and 4).

Table 13 presents the results using the price of teff and a grain price index for the rural sample. ${ }^{27}$ The sign of the coefficient on the indicator variable for the harvesting season (round3_4) is in most cases as expected although it is statistically significant only for diet diversity in the specification with the price of teff. The interpretation of the empirical results is as follows: consistent with the main results in Table 9, a higher price of teff improves diet diversity though its effect is much stronger in the lean season than in the harvesting season where its impact is still positive and statistically significant, and diet diversity is already at a high level as presented in column (3). As depicted in columns (1) and (5), the price of teff does

\footnotetext{
${ }^{25}$ The seasonal pattern of diet diversity and calorie consumption is also stable over the different wealth terciles of the rural population (see the online supplementary material).

${ }^{26}$ Using interaction terms for each round reduces the power of the regression due to the high number of explanatory variables.

${ }^{27}$ For reasons of readability, the other grain price indices are omitted and only the grain price index weighed by consumption at the kebele level investigated.
} 
Table 12 Mean food security indicators per round (quarter) and coefficient of variation (CV) over seasonal means

\begin{tabular}{|c|c|c|c|c|c|c|c|c|}
\hline \multirow[t]{2}{*}{ Round (months) } & \multicolumn{2}{|c|}{ less preferred food } & \multicolumn{2}{|c|}{ number of meals } & \multicolumn{2}{|c|}{ diet diversity } & \multicolumn{2}{|c|}{ calories per AEU and day } \\
\hline & urban & rural & urban & rural & urban & rural & urban & rural \\
\hline 1 (Mar-Apr 2012) & $0.41^{\mathrm{a}}$ & $0.48^{\mathrm{a}}$ & 2.76 & 2.61 & 8.31 & 3.78 & 2706 & 1880 \\
\hline 2 (Jun-Jul 2012) & 0.16 & 0.16 & 2.91 & 2.74 & 8.69 & 6.73 & 2495 & 2637 \\
\hline 3 (Oct-Nov 2012) & 0.11 & 0.19 & 2.92 & 2.71 & 8.35 & 7.30 & 2305 & 2754 \\
\hline 4 (Jan-Feb 2013) & 0.28 & 0.28 & 2.82 & 2.80 & 8.80 & 7.15 & 2659 & 2895 \\
\hline Variation $(\mathrm{CV})$ & $48.6 \%$ & $45.3 \%$ & $2.4 \%$ & $2.5 \%$ & $2.5 \%$ & $23.0 \%$ & $6.2 \%$ & $15.4 \%$ \\
\hline
\end{tabular}

a As discussed when describing the data, the question on the consumption of less preferred food refers to a twelve month recall period in the first round and to a three month recall period otherwise. Without controlling for this effect (e.g. as done in our empirical analysis with survey round indicators), the different recall periods do not allow comparing mean values of this variable in the first round to those in subsequent rounds in a meaningful manner

neither influence the consumption of less preferred foods nor calorie consumption in either of the seasons in a statistically significant way, which supports the main results in Tables 7 and 11. With respect to grain prices measured by the price index it is found that higher prices lead to the consumption of less preferred foods, while the effect is slightly stronger in the harvesting season as shown in column (2). This is in line with the main findings reported in Table 7 but points to the fact that rural households tend to switch to less preferred foods in the harvest season not only due to high costs of purchasing grains but also high opportunity costs of consuming the self-produced grain. No statistically significant impact of increases in the price index on diet diversity and calorie consumption in either of the seasons is found which is consistent with the main findings (Table 9 and 11).

To sum up, differentiating price effects according to their impacts in the lean and harvesting seasons supports the main

Table 13 Regression coefficient estimates linking food security to grain prices accounting for seasonality — Rural sample

\begin{tabular}{|c|c|c|c|c|c|c|}
\hline & $(1)$ & (2) & (3) & (4) & $(5)$ & (6) \\
\hline & \multicolumn{2}{|c|}{ less preferred food } & \multicolumn{2}{|c|}{ ln_diet diversity } & \multicolumn{2}{|c|}{ ln_calories per AEU } \\
\hline \multirow[t]{2}{*}{ ln_price_teff } & \multicolumn{2}{|l|}{0.0145} & \multicolumn{2}{|l|}{$0.518^{* * *}$} & \multicolumn{2}{|l|}{0.0889} \\
\hline & \multicolumn{2}{|l|}{$[0.151]$} & \multicolumn{2}{|l|}{$[0.152]$} & \multicolumn{2}{|l|}{$[0.365]$} \\
\hline \multirow[t]{2}{*}{ ln_price_teff*round3_4 } & \multicolumn{2}{|l|}{0.0844} & \multicolumn{2}{|l|}{$-0.369^{* *}$} & \multicolumn{2}{|l|}{-0.153} \\
\hline & \multicolumn{2}{|l|}{$[0.146]$} & \multicolumn{2}{|l|}{$[0.146]$} & \multicolumn{2}{|l|}{ [0.346] } \\
\hline \multirow[t]{2}{*}{ ln_price_index_keb } & & $0.308^{* *}$ & & 0.105 & & 0.0383 \\
\hline & & {$[0.127]$} & & {$[0.0873]$} & & [0.249] \\
\hline \multirow[t]{2}{*}{ ln_price_index_keb_*round3_4 } & & 0.0536 & & -0.00436 & & 0.256 \\
\hline & & [0.0997] & & {$[0.0877]$} & & {$[0.270]$} \\
\hline \multirow[t]{2}{*}{ round3_4 } & -0.397 & -0.464 & $1.356^{* * *}$ & 0.462 & 1.023 & -0.398 \\
\hline & [0.393] & {$[0.444]$} & {$[0.393]$} & {$[0.391]$} & [0.917] & [1.202] \\
\hline Marginal effect for price in rounds 3 and 4 & 0.0989 & 0.3612 & 0.1485 & 0.1004 & -0.0637 & 0.2938 \\
\hline F-statistic & 0.58 & 5.45 & 2.78 & 0.66 & 0.08 & 0.97 \\
\hline p-value & 0.4461 & 0.0200 & 0.0959 & 0.4155 & 0.7725 & 0.3256 \\
\hline Household controls & Yes & Yes & Yes & Yes & Yes & Yes \\
\hline Household FE & Yes & Yes & Yes & Yes & Yes & Yes \\
\hline$N$ & 1108 & 1133 & 1104 & 1129 & 989 & 1014 \\
\hline$R^{2}$ & 0.065 & 0.089 & 0.428 & 0.427 & 0.135 & 0.161 \\
\hline
\end{tabular}

Robust standard errors in brackets. The marginal effect is the marginal effect of a price change in rounds 3 and 4 . Instead of indicators for each round, round3_4 is a binary variable denoting an observation being from the third or fourth survey round

${ }^{*} p<0.10,{ }^{* *} p<0.05,{ }^{* * *} p<0.01$ 
results. The effects of the price of teff and other grains on diet diversity and on the likelihood of consuming less preferred foods, respectively, are confirmed. Although the indicators of FNS used here exhibit strong seasonal patterns, this seasonality appears to be more strongly affected by domestic food supply (the harvest of farmers) and by credit constraints for input expenditures than by grain prices. Nevertheless, it should be kept in mind that the data were collected over a period of only one year, which makes disentangling round-specific impacts from 'regular' seasonal effects and rather 'singular' effects that occurred in a specific round during the survey period difficult.

\section{Conclusions}

This study investigates the impact of food price changes on food and nutrition security in urban and rural Ethiopia in the short-term. Using a quarterly household survey panel dataset and price data collected directly at markets, a heterogeneous effect of high cereal prices on nutrition security overall is found, focusing on changes within, rather than across households. Increases in cereal prices are generally, but not in all cases, associated with a lower number of meals consumed in a household and a higher likelihood of less preferred foods being eaten, but with no clear response in relation to diet diversity or the number of calories being consumed. Contrary to existing notions, the results suggest that the effect is negative for both the urban and rural populations, while it is stronger in the former, especially among relatively poor households in the sample used here.

The dataset used here is unique in that it allows a solid econometric analysis including controlling for unobserved heterogeneity at the household as well as survey round and seasonality effects. Furthermore, the availability of price data from 24 local markets gives substantial regional variation in price shocks without the need to calculate imprecise and possibly biased unit prices from information on household expenditure. The inclusion of survey round indicators as well as household fixed effects is an important strength of the analysis even though it leads to a very 'strict' specification in which it is difficult to see any effect as a lot of noise is controlled for. This is particularly important for seasonal effects that influence both prices and consumption, leading to spurious correlation if not controlled for.

The major findings of the analysis are that price spikes in the most important staple grains reduce the frequency of meals and increase the likelihood of consuming less preferred foods in both rural and urban households. The poorest urban households and the ones in the middle of the wealth distribution in the rural area respond primarily by reducing the number of meals, while wealthier households do not need to adjust to grain price changes. Regarding diet quality proxied by the consumption of less preferred foods, the analysis suggests that, in general, households in both samples, but especially poor to medium well off urban households switch to less preferred food items. Although poor households consume fewer calories and eat less diverse types of food, they hardly respond to intra-annual price changes and are able to maintain their food and nutrition intake. This may be grounded in the analysis being set when the food price crisis had already been ongoing for a few years and price changes during the survey period were less extreme than in 2007-08 and 2010, when especially poor households may have sacrificed nutritional quality and intake.

One of the surprising results of our study is that rural households are also negatively affected by increasing food prices (even if not as severely as urban households), at least in the short run. This negative impact may well be reversed in the long run when adjustment processes in production behavior take place and farmers switch to high-price grains, as suggested by Tefera et al. (2013a, b), and Headey (2014). There are, however, several reasons why adjustment is slow: farmers using seeds from their own harvest face high costs of switching to other grains and may, in addition, be subject to cash and credit constraints, especially if they are net food buyers. Farmers may also perceive current price increases as temporary shocks which they expect to normalize in a couple of months. Switching to food crops with currently high prices at the expense of other (cash) crops, in particular perennial plants, is therefore associated with risk. Nonetheless, it is important to differentiate between short-term and long-term impacts of food price changes.

Another interesting finding is related to the role of seasonality: rural households show strong seasonal patterns in food consumption (so do urban households, but to a lesser extent) which are not only related to harvest but also to credit constraints during the planting season. The impacts of prices on calorie consumption and diet diversity do not differ between lean and harvesting season, thereby confirming the rather weak impact of prices on these two food security indicators.

In the currently controversial debate on whether high food prices could be better for the poor than low food prices, our analysis emphasizes the role of intra-annual price shocks on different food security indicators. Besides largely insignificant impacts on calorie consumption and diet diversity, rather negative impacts are found regarding the number of meals and consumption of less preferred food for a large proportion of the urban poor as well as the rural population in Ethiopia. As a food deficit and wheat importing country, food prices in Ethiopia are closely linked to global prices and price shocks. Hence, excessive international as well as 
domestic food price variability is a concern for domestic food security.

Acknowledgments The authors gratefully acknowledge the financial support from the German Federal Ministry for Economic Cooperation and Development (BMZ). We thank Seid Nuru Ali, Joachim von Braun, Mekbib Haile, Carlos Martins-Filho, Evita Pangaribowo, Richard Strange, Doris Wiesmann, and two anonymous referees for helpful comments. All errors are ours.

Open Access This article is distributed under the terms of the Creative Commons Attribution License which permits any use, distribution, and reproduction in any medium, provided the original author(s) and the source are credited.

\section{Appendix A: Calculation of the fraction of households that consume one meal less}

In order to have a better understanding of the magnitude of the impact of cereal price increases on the number of meals being consumed, we transform the marginal effect of a price increase into a different indicator: the share of the population that cuts the number of meals consumed per day by one.
Let $\bar{x}$ be the mean number of average meals consumed in the population before the price change and let $\tilde{x}$ be the mean number of average meals after the price change. Suppose that the change in mean meals occurs because a fraction $\eta$ of households reduces the number of meals by one (i.e. eating $\bar{x}-1$ meals on average) while the other fraction of households $1-\eta$ continues to eat $\bar{x}$ number of meals. Then,

$\tilde{x}=(\bar{x}-1) \eta+(1-\eta) \bar{x}=\bar{x}-\eta$.

The estimated elasticity $\epsilon$, given by the coefficient on a price (index), indicates how strongly mean meals $x$ change for a relative price change $\Delta p / p$, i.e. $\Delta x=\tilde{x}-\bar{x} \approx \varepsilon \bar{x} \Delta p / p$. Together with Eq. 2 this yields:

$\eta=-\Delta x=-\varepsilon \bar{x} \frac{\Delta p}{p}$.

Hence, knowing the price change $\frac{\Delta p}{p}$, the mean number of meals $\bar{x}$ before the price increase and the elasticity $\varepsilon$, we can calculate the share $\eta$ of the population that, on average, consume one meal less per day after the price change with the help of Eq. 3.

\section{Appendix B: Tables}

Table 14 Regression coefficient estimates of alternative specifications linking food security to grain prices - No logarithms of the dependent variable

\begin{tabular}{|c|c|c|c|c|c|c|}
\hline & number of meals & & diet diversity & & calories per AEU & \\
\hline & (1) & (2) & (3) & (4) & (5) & (6) \\
\hline & urban & rural & urban & rural & urban & rural \\
\hline \multirow{2}{*}{ ln_price_teff } & -0.0313 & -0.105 & 0.0220 & 0.222 & -655.2 & $-5634.8^{*}$ \\
\hline & {$[0.0212]$} & {$[0.0924]$} & {$[0.0883]$} & {$[0.400]$} & [525.9] & [3019.7] \\
\hline \multirow[t]{2}{*}{ ln_price_index_hh } & -0.0174 & $-0.126^{*}$ & -0.0827 & 0.383 & -286.0 & 16.48 \\
\hline & {$[0.0291]$} & {$[0.0645]$} & [0.0988] & {$[0.242]$} & {$[675.1]$} & [1671.6] \\
\hline \multirow[t]{2}{*}{ ln_price_index_keb } & -0.0379 & $-0.264^{* *}$ & -0.0172 & 0.386 & -583.0 & -4152.2 \\
\hline & [0.0302] & [0.113] & {$[0.118]$} & {$[0.441]$} & [741.5] & [2989.5] \\
\hline \multirow[t]{2}{*}{ ln_price_index_keb_exteff } & -0.0443 & $-0.282^{* * *}$ & -0.125 & 0.209 & 598.6 & -4117.8 \\
\hline & {$[0.0646]$} & {$[0.0955]$} & {$[0.215]$} & {$[0.418]$} & [1229.1] & [2590.2] \\
\hline \multirow[t]{2}{*}{ ln_price_index_FAO } & -0.0727 & $-0.391^{* * *}$ & -0.0632 & 0.877 & -602.1 & -3253.5 \\
\hline & {$[0.0503]$} & {$[0.142]$} & {$[0.191]$} & {$[0.558]$} & [1091.0] & [3636.4] \\
\hline Household controls & Yes & Yes & Yes & Yes & Yes & Yes \\
\hline Household FE & Yes & Yes & Yes & Yes & Yes & Yes \\
\hline Round dummies & Yes & Yes & Yes & Yes & Yes & Yes \\
\hline$N$ & $882 \leq N \leq 911$ & $1027 \leq N \leq 1130$ & $896 \leq N \leq 925$ & $1024 \leq N \leq 1129$ & $831 \leq N \leq 860$ & $926 \leq N \leq 1016$ \\
\hline$R^{2}$ & $0.063 \leq R^{2} \leq 0.065$ & $0.070 \leq R^{2} \leq 0.082$ & $0.060 \leq R^{2} \leq 0.065$ & $0.522 \leq R^{2} \leq 0.546$ & $0.046 \leq R^{2} \leq 0.048$ & $0.139 \leq R^{2} \leq 0.158$ \\
\hline
\end{tabular}

Robust standard errors in brackets. Separate regressions for each price (index); only the coefficient on the respective price (index) is reported for each regression

${ }^{*} p<0.10,{ }^{* *} p<0.05,{ }^{* * *} p<0.01$ 
Table 15 Regression coefficient estimates of alternative specifications linking food security to grain prices - Poisson, conditional Logit, and calories from grains

\begin{tabular}{|c|c|c|c|c|c|c|}
\hline & \multicolumn{2}{|c|}{ ln_number of meals } & \multicolumn{2}{|c|}{ less preferred food } & \multicolumn{2}{|c|}{ ln_calories per AEU from grains } \\
\hline & (1) & $(2)$ & (3) & (4) & $(5)$ & (6) \\
\hline & urban & rural & urban & rural & urban & rural \\
\hline \multirow[t]{2}{*}{$\ln$ _price_teff } & -0.0107 & -0.0379 & $0.784^{* * *}$ & 1.324 & -0.0267 & -0.0661 \\
\hline & {$[0.00730]$} & {$[0.0328]$} & [0.201] & {$[0.882]$} & {$[0.0360]$} & {$[0.218]$} \\
\hline \multirow[t]{2}{*}{ ln_price_index_hh } & -0.00597 & $-0.0476^{* *}$ & $0.943^{* * *}$ & 0.799 & -0.0398 & $0.187^{*}$ \\
\hline & {$[0.00988]$} & {$[0.0235]$} & {$[0.280]$} & {$[0.602]$} & {$[0.0421]$} & {$[0.111]$} \\
\hline \multirow[t]{2}{*}{ ln_price_index_keb } & -0.0129 & $-0.102^{* *}$ & $1.035^{* * *}$ & $1.896^{* *}$ & -0.0568 & 0.0836 \\
\hline & {$[0.0104]$} & {$[0.0415]$} & {$[0.271]$} & {$[0.836]$} & {$[0.0499]$} & {$[0.240]$} \\
\hline \multirow[t]{2}{*}{ ln_price_index_keb_exteff } & -0.0156 & $-0.107^{* * *}$ & $1.269^{* * *}$ & $1.781^{* *}$ & -0.0800 & 0.0565 \\
\hline & {$[0.0225]$} & {$[0.0350]$} & [0.447] & [0.769] & [0.0909] & {$[0.232]$} \\
\hline \multirow[t]{2}{*}{ ln_price_index_FAO } & -0.0251 & $-0.151^{* * *}$ & $1.494^{* * *}$ & $1.494^{* * *}$ & -0.0948 & 0.0656 \\
\hline & {$[0.0172]$} & {$[0.0530]$} & {$[0.424]$} & {$[0.424]$} & {$[0.0786]$} & {$[0.307]$} \\
\hline Household controls & Yes & Yes & Yes & Yes & Yes & Yes \\
\hline Household FE & Yes & Yes & Yes & Yes & Yes & Yes \\
\hline Round dummies & Yes & Yes & Yes & Yes & Yes & Yes \\
\hline$N$ & $820 \leq N \leq 849$ & $919 \leq N \leq 1003$ & $438 \leq N \leq 443$ & $443 \leq N \leq 593$ & $820 \leq N \leq 845$ & $854 \leq N \leq 920$ \\
\hline Wald $\chi^{2}$ & \multicolumn{6}{|c|}{$37.92 \leq \chi^{2} \leq 39.0142 .42 \leq \chi^{2} \leq 46.10$} \\
\hline \multicolumn{3}{|l|}{ McFadden's $R^{2}$} & \multicolumn{4}{|c|}{$0.328 \leq R^{2} \leq 0.3560 .184 \leq R^{2} \leq 0.215$} \\
\hline \multicolumn{3}{|l|}{$R^{2}$} & & & \multicolumn{2}{|c|}{$0.029 \leq R^{2} \leq 0.0330 .045 \leq R^{2} \leq 0.058$} \\
\hline
\end{tabular}

Standard errors in brackets. Robust standard errors in columns (1), (2), (5), (6), jackknife standard errors in columns (3) and (4). Poisson estimation in columns (1) and (2), conditional Logit in columns (3) and (4), and standard fixed effects estimation in columns (5) and (6). Separate regressions for the each price (index); only the coefficient on the respective price (index) is reported for each regression

${ }^{*} p<0.10,{ }^{* *} p<0.05,{ }^{* * *} p<0.01$

\section{References}

Aksoy, M.A., \& Isik-Dikmelik, A. (2008). Are Low Food Prices Pro-Poor? Net Food Buyers and Sellers in Low-Income Countries. The World Bank Policy Research Working Paper No, 4642.

Alem, Y., \& Söderbom, M. (2012). Household-level consumption in urban Ethiopia: the effects of a large food price shock. World Development, 40(1), 146-162.

Anríquez, G., Daidone, S., \& Mane, E. (2013). Rising food prices and undernourishment: a cross-country inquiry. Food Policy, 38, 190202.

Arimond, M., \& Ruel, M.T. (2004). Dietary diversity is associated with child nutritional status: evidence from 11 demographic and health surveys. The Journal of Nutrition, 134(10), 2579-2585.

De Hoyos, R.E., \& Medvedev, D. (2011). Poverty effects of higher food prices: a global perspective. Review of Development Economics, 15(3), 387-402.

Dercon, S., \& Krishnan, P. (1998). Changes in poverty in rural Ethiopia 1989-1995: measurement, robustness tests and decomposition. Centre for the Study of African Economies CSAE Working Paper Series No. 1998-07.

D'Souza, A., \& Jolliffe, D. (2014). Food insecurity in vulnerable populations: coping with food price shocks in Afghanistan. American Journal of Agricultural Economics, 96(3), 790812.
Ethiopian Economics Association (2011). Financial sector development in Ethiopia: performance challenges and issues. Report on the Ethiopian Economy.

Ethiopian Economics Association (2013). Private sector development in Ethiopia with particular emphasis to the manufacturing sector. Report on the Ethiopian Economy.

FAOSTAT. (2013). Food balance sheets. FAO: Rome.

Federal Democratic Republic of Ethiopia Central Statistical Agency (2009). Statistical tables for the 2007 population and housing census of Ethiopia. Addis Ababa.

Federal Democratic Republic of Ethiopia Central Statistical Agency (2012). Household Consumption and Expenditure (HCE) Survey 2010/11. Analytical Report. Statistical Bulletin 563. Addis Ababa.

Federal Democratic Republic of Ethiopia Central Statistical Agency (2013). Agricultural Sample Survey 2012/2013 (2005 E.C.). Volume I Report on Area and Production of Major Crops (Private Peasant Holdings, Meher Season). Statistical Bulletin 532. Addis Ababa.

Greb, F., Jamora, N., Mengel, C., von Cramon-Taubadel, S., \& Würriehausen, N. (2012). Price transmission from international to domestic markets. Courant Research Centre: Poverty, Equity and Growth -Discussion Paper No. 125.

Headey, D., Fantu, B.N., Worku, I., Dereje, M., \& Taffesse, A.S. (2012). Urban wage behaviour and food price inflation: The case 
of Ethiopia. Ethiopia strategy support program II (ESSP II). ESSP II Working Paper No. 41.

Headey, D.D. (2014). Food prices and poverty reduction in the long run. Discussion Paper 01331, International Food Policy Research Institute (IFPRI).

Hoddinott, J., \& Yohannes, Y. (2002). Dietary diversity as a food security indicator. FCND briefs No. 136, International Food Policy Research Institute.

Ianchovichina, E., Loening, J., \& Wood, C. (2012). How vulnerable are Arab countries to global food price shocks? World Bank Policy Research Working Paper No. 6018.

Iannotti, L., \& Robles, M. (2011). Negative impact on calorie intake associated with the 2006-08 food price crisis in Latin America. Food \& Nutrition Bulletin, 32(2), 112-123.

Iannotti, L.L., Robles, M., Pachón, H., \& Chiarella, C. (2012). Food prices and poverty negatively affect micronutrient intakes in Guatemala. The Journal of Nutrition, 142(8), 1568-1576.

Ivanic, M., \& Martin, W. (2008). Implications of higher global food prices for poverty in low-income countries. Agricultural Economics, 39(s1), 405-416.

Jensen, R.T., \& Miller, N.H. (2008a). Giffen Behavior and Subsistence Consumption. American Economic Review, 98(4), 1553-1577.

Jensen, R.T., \& Miller, N.H. (2008b). The impact of food price increases on caloric intake in China. Agricultural Economics, 39(s1), 465-476.

Kalkuhl, M. (2014). How strong do global commodity prices influence domestic food prices in developing countries?, A Global Price Transmission and Vulnerability Mapping Analysis. ZEFDiscussion Papers on Development Policy, 191.

Kalkuhl, M., Kornher, L., Kozicka, M., Boulanger, P., \& Torero, M. (2013). Conceptual framework on price volatility and its impact on food and nutrition security in the short term. FoodSecure Working Paper No. 15.

Robles, M. (2011). Price transmission from international agricultural commodity markets to domestic food prices: Case Studies in Asia and Latin America. Washington D.C.: International Food Poliy Research Institute.

Shimeles, A., \& Delelegn, A. (2013). Rising food prices and household welfare in Ethiopia: evidence from micro data. African Development Bank Group Working Paper No. 182.

Shin, M. (2010). A geospatial analysus of market integration: the case of the 2004/5 food crisis in Niger. Food Security, 2(3), 261-269.

Smith, L.C., \& Haddad, L.J. (2000). Explaining child malnutrition in developing countries: A cross-country analysis. Washington D.C.: International Food Poliy Research Institute.

Smith, L.C., \& Subandoro, A. (2007). Measuring food security using household expenditure surveys. Washington D.C.: International Food Poliy Research Institute.

Tefera, N., Demeke, M., Rashid, S., \& Kayitakire, F. (2013a). Do rural farming households benefit from high food prices? Food and Nutrition Security Policy Implications in 18 Villages. Unpublished manuscript.

Tefera, N., Demeke, M., Rashid, S., \& Kayitakire, F. (2013b). High Food Prices and Household Food Demand Patterns in Ethiopia: Panel Evidence from 18 rural Villages. Unpublished manuscript.

Ticci, E. (2011). Can inflation be a good thing for the poor? evidence from Ethiopia. Development in Practice, 21(4-5), 629-641.

Tiwari, S., \& Zaman, H. (2010). The impact of economic shocks on global undernourishment. World Bank Policy Research Working Paper No. 5215.

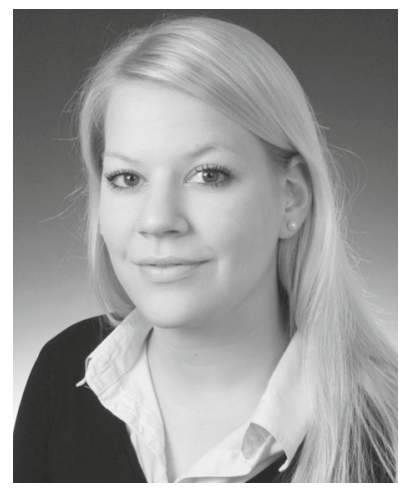

Julia Anna Matz is a postdoctoral researcher at the Center for Development Research (ZEF) of the University of Bonn, Germany. After studying International Economics and Business at the Rijkuniversiteit Groningen in the Netherlands and African Studies in Hamburg, Germany, she completed her $\mathrm{PhD}$ in Economics at Trinity College Dublin, Ireland, in 2013. Her research interests are mainly in the fields of applied economics of the family and the household including intra-household analyses, poverty, migration, and female empowerment in developing countries.

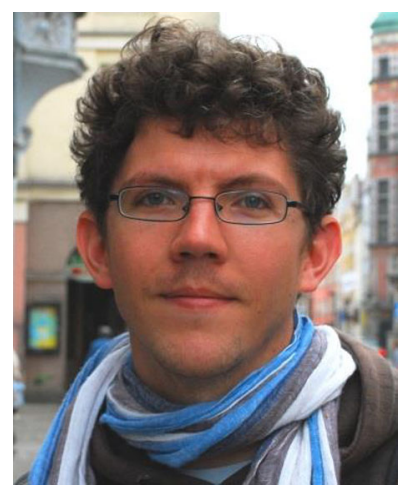

Matthias Kalkuhl studied Applied System Science and Economics in Osnabrück and Berlin, Germany. He is researcher and project coordinator of the project "Food Price Volatility, Trade Policy and the Poor" at the Center for Development Research (ZEF) at the University of Bonn, Germany. His research focuses on empirical, theoretical and quantitative analysis of food security, agricultural markets, environmental and development issues. Before joining ZEF in March 2012, he was research associate at the Potsdam Institute for Climate Impact Research, Potsdam, Germany, where he worked on economic models for climate policy analysis.

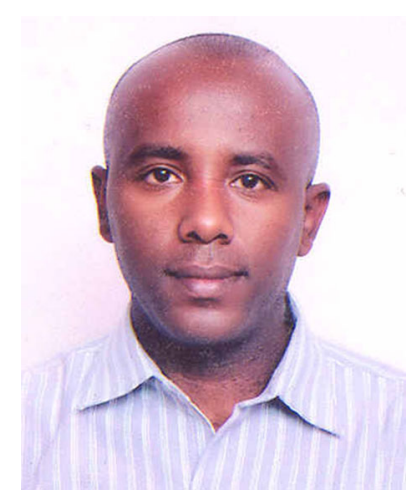

Getachew Ahmed Abegaz is a research collaborator at the International Food Policy Research Institute (IFPRI) in Addis Ababa, Ethiopia. He worked for the Ethiopian Economics Association and the National Bank of Ethiopia before joining IFPRI. His research interests are in the area of poverty, vulnerability, economic growth, farm productivity, and the economics of technology, institutions, and public policy. Getachew graduated from Addis Ababa University in 2009 with a Master's of Science in Economic Policy Analysis. 